\title{
Marine boundary layer cloud regimes and POC formation in a CRM coupled to a bulk aerosol scheme
}

\author{
A. H. Berner ${ }^{1}$, C. S. Bretherton ${ }^{1}$, R. Wood ${ }^{1}$, and A. Muhlbauer ${ }^{2}$ \\ ${ }^{1}$ Department of Atmospheric Science, University of Washington, Seattle, Washington, USA \\ ${ }^{2}$ Joint Institute for the Study of the Atmosphere and Ocean, University of Washington, Seattle, Washington, USA
}

Correspondence to: A. H. Berner (andy.berner@gmail.com)

Received: 21 June 2013 - Published in Atmos. Chem. Phys. Discuss.: 8 July 2013

Revised: 21 November 2013 - Accepted: 22 November 2013 - Published: 23 December 2013

\begin{abstract}
A cloud-resolving model (CRM) coupled to a new intermediate-complexity bulk aerosol scheme is used to study aerosol-boundary-layer-cloud-precipitation interactions and the development of pockets of open cells (POCs) in subtropical stratocumulus cloud layers. The aerosol scheme prognoses mass and number concentration of a single lognormal accumulation mode with surface and entrainment sources, evolving subject to processing of activated aerosol and scavenging of dry aerosol by clouds and rain.
\end{abstract}

The CRM with the aerosol scheme is applied to a range of steadily forced cases idealized from a wellobserved POC. The long-term system evolution is explored with extended two-dimensional (2-D) simulations of up to 20 days, mostly with diurnally averaged insolation and $24 \mathrm{~km}$ wide domains, and one 10 day threedimensional (3-D) simulation. Both 2-D and 3-D simulations support the Baker-Charlson hypothesis of two distinct aerosol-cloud "regimes" (deep/high-aerosol/non-drizzling and shallow/low-aerosol/drizzling) that persist for days; transitions between these regimes, driven by either precipitation scavenging or aerosol entrainment from the free-troposphere (FT), occur on a timescale of ten hours. The system is analyzed using a two-dimensional phase plane with inversion height and boundary layer average aerosol concentrations as state variables; depending on the specified subsidence rate and availability of FT aerosol, these regimes are either stable equilibria or distinct legs of a slow limit cycle.

The same steadily forced modeling framework is applied to the coupled development and evolution of a POC and the surrounding overcast boundary layer in a larger $192 \mathrm{~km}$ wide domain. An initial $50 \%$ aerosol reduction is applied to half of the model domain. This has little effect until the stratocumu- lus thickens enough to drizzle, at which time the low-aerosol portion transitions into open-cell convection, forming a POC. Reduced entrainment in the $\mathrm{POC}$ induces a negative feedback between the areal fraction covered by the POC and boundary layer depth changes. This stabilizes the system by controlling liquid water path and precipitation sinks of aerosol number in the overcast region, while also preventing boundary layer collapse within the POC, allowing the POC and overcast to coexist indefinitely in a quasi-steady equilibrium.

\section{Introduction}

Marine stratocumulus clouds cover broad swaths of the world ocean, exerting a strong net radiative cooling effect on climate due to their high albedo (Hartmann et al., 1992). The turbulent circulations maintaining marine stratocumulus are on the order of the boundary layer thickness $(1 \mathrm{~km})$, far below the spatial scale resolved by global climate models (GCMs). Marine stratocumulus clouds are thin (100-500 m deep), and are usually capped by a sharp, strong temperature inversion. These sharp gradients are not resolved by GCMs and a challenge to parameterize. They are maintained by strong feedbacks between turbulence, cloudiness, radiation, aerosols and precipitation; in a GCM these are parameterized processes involving substantial subgrid variability. These factors combined make marine stratocumulus a key challenge for simulating climate, including two central uncertainties in simulating anthropogenic climate change boundary layer cloud feedbacks (Bony and Dufresne, 2005) and cloud-aerosol interaction (Quaas et al., 2009). 
Cloud microphysical properties are modulated by natural and anthropogenic sources of cloud condensation nuclei $(\mathrm{CCN})$. Their influence on net cloud radiative forcing is usually discussed in terms of the first and second aerosol indirect effects. The first indirect effect (Twomey, 1977) refers to the increase of cloud albedo for constant liquid water path (LWP) when cloud droplet number concentration $\left(N_{\mathrm{d}}\right)$ is increased. The second indirect effect relates changes in aerosol number concentration $\left(N_{\mathrm{a}}\right)$ to impacts on albedo via cloud macrophysical properties, such as fractional cloud cover, LWP, and lifetime, due to the interaction of microphysics and cloud dynamics (Albrecht, 1989; Liou and Ou, 1989; Stevens and Feingold, 2009).

Cloud microphysics and dynamics also affect the aerosol. For instance, the droplet collision-coalescence that forms precipitation also reduces $N_{\mathrm{a}}$, increasing cloud droplet size and further enhancing precipitation in a positive feedback loop. Baker and Charlson (1990) suggested that this feedback process could lead a cloud layer to evolve toward one of two very different aerosol concentrations ("multiple equilibria") for a single set of large-scale forcings. Their simple, steady-state model was based on a mixed layer capped by a stratocumulus cloud of fixed liquid water content (LWC). They predicted marine boundary layer (MBL) aerosol concentration given a specified surface aerosol source, treating aerosol sinks due to coagulation, collision-coalescence, and drizzle fall out. Over a typically observed range of aerosol source strengths, their model predicted that an MBL with initial $N_{\mathrm{a}}$ below a threshold value would evolve toward a drizzling state with an aerosol concentration of $\sim 10 \mathrm{~cm}^{-3}$ and small cloud albedo, while an MBL with initial $N_{\mathrm{a}}$ above the threshold value would evolve toward a non-precipitating state with very high aerosol concentration of $\sim 1000 \mathrm{~cm}^{-3}$ and much larger cloud albedo. Ackerman et al. (1994) approached the same problem using a column model including a cloud layer which responded to the aerosol, parameterized turbulent vertical transports, sophisticated microphysics and radiation. Unlike Baker and Charlson (1990), they found no evidence for bistability, obtaining instead a smooth increase in equilibrium aerosol concentration with source strength, because the total aerosol sink term in their model was an increasing function of $N_{\mathrm{a}}$. The relevance of aerosol bistability to real stratocumulus cloud regimes remains an open question.

An observable manifestation of a positive aerosol-cloud feedback and perhaps of bistability is the formation of pockets of open cells, or POCs (Stevens et al., 2005), low-albedo regions of cumuliform, open-cellular convection embedded within a sheet of high-albedo, closed-cell stratocumulus convection. Early aircraft observations of POCs during the EPIC (Bretherton et al., 2004) and DYCOMS-II (Stevens et al., 2003) field campaigns (Comstock et al., 2005, 2007; van Zanten and Stevens, 2005) documented the contrasts between POCs and surrounding stratocumulus regions. Subsequent observations indicated that the aerosol concentra- tion within POCs is also highly depleted, especially in an "ultra-clean layer" just below the inversion (Petters et al., 2006; Wood et al., 2011a). Satellite observations showed POCs form preferentially in the pre-dawn hours, when stratocumulus cloud is typically thickest and most heavily drizzling, and persist once formed (Wood et al., 2008). The VOCALS Regional Experiment (REx; Wood et al., 2011b) in September-October 2008, targeting the massive and persistent stratocumulus deck off the west coast of Chile, was designed in part to systematically document POC structure. VOCALS Research Flight 06 comprehensively sampled a mature POC one day after its formation, providing an invaluable data set for modeling and analysis (Wood et al., 2011a). Four other POCs were also sampled by the NCAR/NSF C130 during VOCALS-REx (Wood et al., 2011b). However, observations alone cannot definitively explain how POCs are formed and maintained - this requires a model, and the challenges of resolution and parameterization uncertainties make GCMs non-ideal for this task.

One type of simplified cloud-aerosol modeling approach (Koren and Feingold, 2011) idealizes open cells as a coupled pair of delay-differential equations for the depth of a cloud and aerosol concentration. Conditional instability feeds the growth of a cumulus cloud, which dissipates due to rain production at a rate affected by the aerosol; the resulting equations can have both stable equilibria and limit cycles depending on the parameters. This approach focuses on the cell-scale dynamics of the convection and is most useful for understanding the lifecycle of individual convective updrafts and cells. To understand the long-term evolution of a whole cloud-aerosol system made of many interacting cells requires the treatment of slow processes that are beyond the scope of such a model, such as cloud-top entrainment, which affects the boundary layer depth, cloud-radiation interaction, and a more careful treatment of boundary layer aerosol sources and sinks.

To this end, cloud-resolving model (CRM) simulations of the MBL are an attractive means to understand the complexities of stratocumulus-aerosol-precipitation interaction and their role in POC formation and maintenance. Here, the term CRM refers to a two- or three-dimensional simulation permitting cloud-producing eddy motions with horizontal length scales at least as fine as the turbulent layer depth. Thus CRMs of MBL turbulence and clouds explicitly simulate the larger, most energetic motions that dominate turbulent fluxes. Large-eddy simulation (LES) models are a type of 3-D CRM in which the dominant eddy scales of turbulent kinetic energy production are well resolved, allowing the development of a plausible turbulent energy cascade. Like GCMs, CRMs require parameterizations of moist thermodynamics, cloud microphysics, radiation, and subgrid turbulence, but they do not require the elaborate, contrived formulations of subgrid variability that make these parameterizations complex and uncertain in GCMs. Early LES studies of aerosol impacts on cloud dynamics included Kogan et al. (1995), Ackerman et 
al. (2003) and Ackerman et al. (2004), which examined the response of small-domain simulations of marine stratocumulus to specified changes in aerosol or cloud droplet concentration. Their simulations found a low-aerosol, heavy drizzle regime in which the cloud cover increased and thickened with more aerosol and a higher aerosol, nearly non-drizzling regime in which the cloud thinned with more aerosol.

Recent modeling studies in domains with sizes on the order of tens of kilometers have examined the influence of aerosol changes on the ubiquitous mesoscale cellular variability in stratocumulus cloud regimes (Wood and Hartmann, 2006). Some studies focused on cloud response to specified $N_{\mathrm{d}}$ or aerosol. Savic-Jovcic and Stevens (2008) and Xue et al. (2008) found increased open-cellular organization with decreasing cloud droplet or aerosol concentration, though the simulations did not exhibit as marked a decrease in cloud cover as found in POCs. Berner et al. (2011) simulated the VOCALS-REx RF06 POC case, imposing observationally based $N_{\mathrm{d}}$ differences between the POC and the surrounding overcast region, and reasonably reproduced the observed contrasts in cloud, precipitation and boundary layer structure across the POC boundary. Their simulations also revealed that the overcast region entrained much more strongly than inside the POC, yet the mean inversion height across the domain remained essentially level, with mesoscale circulations compensating for the reduced entrainment in the POC.

A full understanding of the role of aerosol-cloud interactions in the climate system requires simulation of the feedback of cloud processes on aerosols. For this purpose, several models have added a simple CCN budget including a number sink due to precipitation-related processes. Mechem and Kogan (2003) used this approach in a mesoscale model (not an LES) with a horizontal resolution of $2 \mathrm{~km}$. They simulated transitions from aerosol-rich stratocumulus layers to aerosol-poor, precipitating layers with partial cloud cover. Mechem et al. (2006) also included a prescribed surface CCN source and varying free troposphere (FT) CCN concentration. They identified entrainment of FT CCN as an important buffering mechanism for MBL CCN, because the surface $\mathrm{CCN}$ source is often too weak to balance the collisioncoalescence sink. Subsequent studies have used LES with simple CCN budgets in mesoscale-size domains. Wang and Feingold (2009a) used $300 \mathrm{~m}$ (barely eddy-resolving) resolution to look at the evolution of a stratocumulus layer with three initial CCN concentrations, finding sensitivities similar to Mechem and Kogan (2003). Wang and Feingold (2009b) used a $60 \mathrm{~km} \times 180 \mathrm{~km}$ domain with an initial linear gradient in $\mathrm{CCN}$, showing that the development of open-cell organization smoothly increased as initial CCN decreased. Wang et al. (2010) showed that POCs could be rapidly triggered by reducing the initial aerosol concentration in a mesoscale region within a solid stratocumulus layer, and that the resulting aerosol perturbations and POC structure persist for the $8 \mathrm{~h}$ length of their simulation. They also showed that depending on the initial aerosol concentration, a stratocumulus- capped boundary layer with the same initial cloud characteristics could either quickly transition into open cells that further reduced aerosol concentration, or persist in a highaerosol, nearly non-precipitating state for the length of a $36 \mathrm{~h}$ simulation.

Several LES studies have also included more complete models of aerosol processes in cloud-topped boundary layers. Feingold et al. (1996) coupled bin aerosol microphysics to a 2-D CRM and analyzed the role of aqueous chemistry. Feingold and Kreidenweis (2002) explored the effects of different initial aerosol distributions and aqueous chemistry on cloud dynamics over periods of up to eight hours, and coined the term "runaway precipitation sink" for the increasingly efficient removal of aerosol via precipitation processes at lower values of $N_{\mathrm{d}}$. Ivanova and Leighton (2008) implemented a three mode, two moment bulk aerosol scheme within a mesoscale model based on the approximation that aerosol mass within rain or cloud water droplets is proportional to their water mass, but coagulates into one aerosol particle per droplet, as first suggested by Flossmann et al. (1985) and experimentally verified by Mitra et al. (1992). This approach allows for the inclusion of relatively complete aerosol microphysics with a minimum of additional advected scalars. Kazil et al. (2011) coupled detailed aerosol and gas chemistry into an LES to simulate open-cell convection within the VOCALS RF06 POC, obtaining a realistic simulation of the vertical distribution of aerosol and of the ultra-clean layer, and simulating an episode of spontaneous nucleation of new aerosols within the ultra-clean layer. Arguably, this is the most realistic LES depiction of coupled aerosol-stratocumulus-cloud-precipitation interactions to date.

In this paper, we build on these prior aerosol-cloudprecipitation studies by using 2-D and 3-D CRM simulations to analyze the multiday evolution and equilibrium states of the coupled stratocumulus-cloud-aerosol system subject to a range of constant forcings and initial conditions. We recognize that in reality, MBL air is always advecting over a changing SST and subject to changing synoptic forcings and free-tropospheric conditions. However, it is still reasonable to ask whether one can define preferred "regimes" through which the aerosol-cloud system tends to evolve, and if so, whether the system can be expected to evolve between regimes smoothly or via rapid transitions, whether the system evolution is sensitive to small changes in the external forcings or initial conditions, and possible implications for the bistability of the coupled stratocumulus-cloud-aerosol system.

For this purpose, we couple to our CRM a new intermediate-complexity single-mode, double-moment bulk aerosol scheme inspired by Ivanova and Leighton (2008). In addition to the processes usually included in simple $\mathrm{CCN}$ predicting schemes (parameterized surface source, entrainment from the FT, collision-coalescence, and precipitation fall out), we include interstitial scavenging by cloud and 
rain, which we find to be an important number sink in less heavily precipitating stratocumulus. Unlike a full-complexity aerosol-chemistry scheme like that of Kazil et al. (2011), our scheme requires fewer advected scalars and is still computationally efficient enough for the extended runs used for the present study.

The rest of the paper is organized as follows: Sect. 2 describes the CRM and the new aerosol scheme. Section 3 describes how our simulations are initialized and forced, and Sect. 4 gives an overview of them. In Sect. 5, we examine the evolution of several small-domain 2-D simulations and one comparison 3-D simulation through several cloud regimes. Section 6 examines sensitivity of these results to the mean subsidence rate, the availability of FT aerosol and the diurnal cycle of insolation. In Sect. 7, we examine the evolution of a set of identically forced but differently initialized simulations using a phase plane analysis to discuss MBL cloud regimes and transitions. Finally, in Sect. 8, we use large-domain 2$\mathrm{D}$ runs initialized with a localized region of somewhat reduced aerosol concentration to examine the formation and long-term stability of a POC, a coupled system comprised of two cloud regimes - open cells and the surrounding overcast stratocumulus.

\section{Model formulation}

The simulations in this paper are performed using version 6.9 of the System for Atmospheric Modeling (SAM; Khairoutdinov and Randall, 2003). SAM uses an anelastic dynamical core. An $f$-plane approximation with Coriolis force appropriate for the specified latitude is used. In our simulations, the clouds are liquid phase only, and water mass is partitioned into vapor mixing ratio $q_{\mathrm{v}}$, cloud water mixing ratio $q_{\mathrm{c}}$ (drops smaller than 25 micron radius), and rain water mixing ratio $q_{\mathrm{r}}$ (drops larger than 25 micron radius). These mixing ratios are separately advected in our version, along with liquid-ice static energy $s_{\mathrm{li}}=c_{\mathrm{p}} T+g z-\mathrm{Lq}_{\mathrm{l}}$ (neglecting ice). Here $c_{\mathrm{p}}$ is the isobaric heat capacity of air, $g$ is gravity, $z$ is height, $L$ is the latent heat of vaporization, and the liquid water mixing ratio $q_{1}$ is the sum of $q_{\mathrm{c}}$ and $q_{\mathrm{r}}$. Microphysical tendencies are computed using two-moment Morrison microphysics (Morrison and Grabowski, 2008; Morrison et al., 2005), which requires that we also prognose a cloud water number concentration $N_{\mathrm{d}}$ and a rain number concentration $N_{\mathrm{r}}$; saturation adjustment is used to repartition between $q_{\mathrm{v}}$ and $q_{\mathrm{c}}$ during each time step. Within Morrison microphysics, we use the Khairoutdinov and Kogan (2000)-based precipitation parameterization option, as this scheme was developed for the stratocumulus regime. We have modified SAM to advect scalars using the selective piecewise-parabolic method of Blossey and Durran (2008), which is less numerically diffusive than SAM's default advection scheme. The 1.5 order TKE scheme of Deardorff (1980) is used as the sub-grid turbulence closure (SGS). The SGS length scale is chosen as the vertical grid spacing, as this inhibits unrealistically large mixing on the highly anisotropic grids (large horizontal relative to vertical spacing) needed to efficiently resolve both the inversion and mesoscale structure in stratocumulus LESs. Surface fluxes are computed in each column from Monin-Obukhov theory. Radiation is calculated every $15 \mathrm{~s}$ using the rapid radiative transfer model (RRTM; Mlawer et al., 1997); the solar zenith angle is set for the VOCALS RF06 POC location at $17.5^{\circ} \mathrm{S}$, $79.5^{\circ} \mathrm{W}$. Drizzle has been included in the radiation calculation by specifying a combined cloud-drizzle water effective radius within each grid cell, computed to give the sum of the optical depths due separately to cloud and drizzle drops in that grid layer; aerosol is not included in the radiation calculation since in a remote marine environment, the aerosol optical depth is typically small and the dominant aerosol types do not strongly absorb solar radiation (Allen et al., 2011).

\subsection{Single-mode aerosol scheme}

We have implemented a new, computationally efficient, single-mode, double-moment aerosol scheme for warm clouds which tightly couples with Morrison microphysics, including surface fluxes, entrainment, collision-coalescence, evaporation, and scavenging of interstitial aerosol. The aerosol is described by a single lognormal distribution with prognostic mass and number concentration, loosely approximating the accumulation mode. All the aerosol is assumed to be equally hygroscopic, with the properties of ammonium sulfate. Where condensate (either cloud or rain water) is present, we assume that the "wet" fraction of the distribution that resides in the condensate particles will correspond to the largest (and hence most easily activated) aerosol particles.

A schematic representation of the various source, sink, and transfer terms for mass and number, considered in the MBL mean, is shown in Fig. 1. We follow the approximation of Flossmann et al. (1985) that activated aerosol mass $q_{\mathrm{aw}}$ is affected by moist processes in proportion to the cloud water mass $q_{\mathrm{c}}$, and similarly for rain aerosol mass $q_{\mathrm{ar}}$ vs. rain water mass $q_{\mathrm{r}}$ :

$$
\begin{aligned}
& \left.\frac{\mathrm{d} q_{\mathrm{aw}}}{\mathrm{d} t}\right|_{\mu \mathrm{p}}=q_{\mathrm{aw}}\left(\left.\frac{\mathrm{d} q_{\mathrm{c}}}{\mathrm{d} t}\right|_{\mu \mathrm{p}} / q_{\mathrm{c}}\right), \\
& \left.\frac{\mathrm{d} q_{\mathrm{ar}}}{\mathrm{d} t}\right|_{\mu \mathrm{p}}=q_{\mathrm{ar}}\left(\left.\frac{\mathrm{d} q_{\mathrm{r}}}{\mathrm{d} t}\right|_{\mu \mathrm{p}} / q_{\mathrm{r}}\right),
\end{aligned}
$$

where $\left.\right|_{\mu p}$ denotes tendencies due to microphysics. Including the effects of aerosol in this way requires prognosing and advecting only four additional scalars, namely dry aerosol number concentration $\left(N_{\mathrm{ad}}\right)$ and mass mixing ratio $\left(q_{\mathrm{ad}}\right)$, activated aerosol mass mixing ratio in cloud $\left(q_{\text {aw }}\right)$, and aerosol mass mixing ratio in rain $\left(q_{\mathrm{ar}}\right)$. We assume that the aerosol is fully soluble within condensate and produces a single particle upon evaporation of a cloud or rain drop. At any time, the total aerosol concentration and mass that define the lognormal 


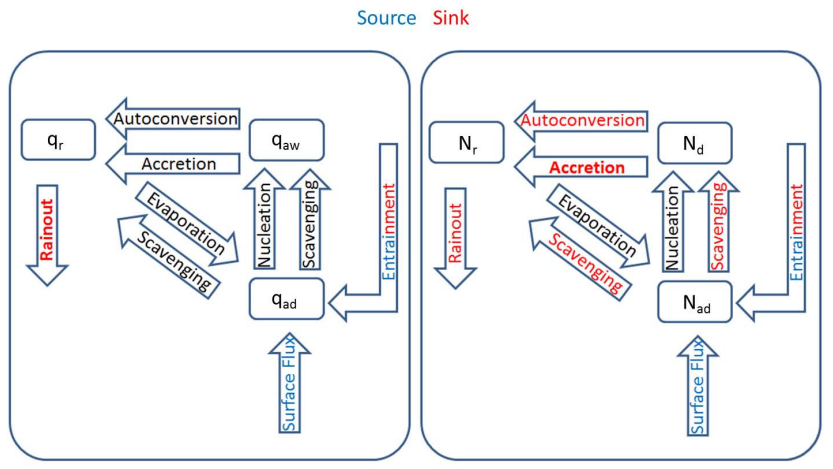

Fig. 1. Block diagram of processes changing the reservoirs of aerosol mass (left) and number (right) in our bulk aerosol scheme; colors indicate processes that are MBL-mean source or sinks (Entrainment is shown in both colors since it can be either a source or sink.)

distribution are the sum of components from the dry (unactivated) aerosol, cloud droplets and rain drops:

$\begin{aligned} N_{\mathrm{a}} & =N_{\mathrm{ad}}+N_{\mathrm{d}}+N_{\mathrm{r}}, \\ q_{\mathrm{a}} & =q_{\mathrm{ad}}+q_{\mathrm{aw}}+q_{\mathrm{ar}} .\end{aligned}$

Ivanova and Leighton included three modes in their scheme: unprocessed aerosol, cloud-processed aerosol, and a coarse mode resulting from evaporated precipitation. By simplifying their approach to a single accumulation mode, we keep the process complexity and the number of auxiliary scalar fields to a minimum, while retaining the size range relevant to cloud droplet activation. We carry the aerosol mass mixing ratio in addition to number concentration, because the droplet activation parameterization of Abdul-Razzak and Ghan (2000) used by the Morrison microphysics scheme requires these aerosol parameters, as does our newly developed scavenging parameterization for interstitial aerosol. In this parameterization, described further in the Appendix, $q_{\mathrm{ad}}$ and $N_{\text {ad }}$ tendencies are computed using the cloud and raindrop size spectra from the Morrison scheme, together with approximate collection kernels for convective Brownian diffusion, thermophoresis, diffusiophoresis, turbulent coagulation, interception, and impaction. While interstitial scavenging has been ignored in several other studies, cloud droplets have a reasonably high collection efficiency for unactivated accumulation-mode aerosol (Zhang et al., 2004).

Surface fluxes are computed using a modified version of the wind speed dependent sea salt parameterization of Clarke et al. (2006), where we have refit the size-resolved fluxes with a single, lognormal accumulation mode. As we are concerned mainly with particles at sizes where they will be viable $\mathrm{CCN}$, we choose to center the source distribution about the geometric radius of $0.13 \mu \mathrm{m}$. To include the number and mass contributions from the smaller and most numerous portion of the coarse mode, as well as the smallest end of the accumulation mode that may be active $\mathrm{CCN}$ at higher super-

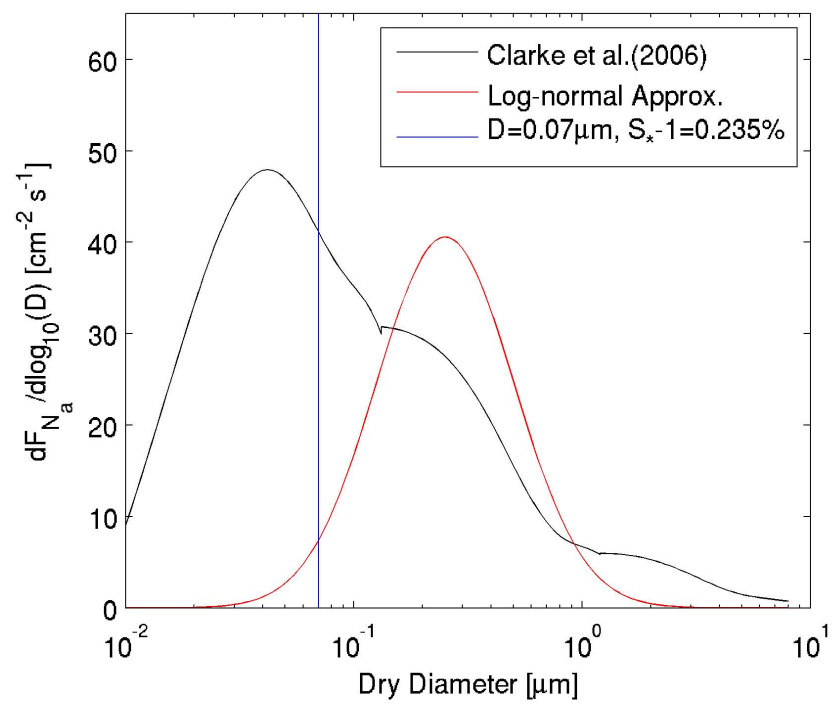

Fig. 2. Clarke et al. (2006) size-resolved sea-salt aerosol number flux and unimodal CCN approximation used in this study, plotted for $u_{10}$ of $9 \mathrm{~m} \mathrm{~s}^{-1}$. Blue vertical line indicates cutoff for viable $\mathrm{CCN}$ at $0.07 \mu \mathrm{m}$. All aerosol particles in this study are assumed to have the properties of ammonium sulfate.

saturations, we choose a distribution width parameter $\sigma_{\mathrm{g}}=2$. We then choose an aerosol number source that gives $50 \%$ of the total integrated number flux in the distribution given by Clarke et al. (2006); the remaining particles being assessed to be too small to act as $\mathrm{CCN}$.

$$
\begin{aligned}
& \left.\frac{\mathrm{d} N_{\mathrm{ad}}}{\mathrm{d} t}\right|_{\mathrm{Srf}}=1.706 \times 10^{2} U_{10}^{3.41} \mathrm{~m}^{-2} \mathrm{~s}^{-1} \\
& \left.\frac{\mathrm{d} q_{\mathrm{ad}}}{\mathrm{d} t}\right|_{\text {Srf }}=2.734 \times 10^{-19} U_{10} 3.41 \mathrm{~kg} \mathrm{~m}^{-2} \mathrm{~s}^{-1}
\end{aligned}
$$

The mass flux is only $0.5 \%$ of that given by Clarke et al. (2006), which was dominated by coarse-mode aerosols bigger than the range of sizes across which our fit is optimized. Figure 2 plots the size-resolved mass and number fluxes at a windspeed of $9 \mathrm{~m} \mathrm{~s}^{-1}$ for the Clarke et al. (2006) parameterization against our unimodal approximation.

Aerosol in the free troposphere can be brought into the cloud layer through model-simulated entrainment. Observations suggest that over remote parts of the oceans, the FT generally has a substantial number concentration of aerosol particles that can act as CCN (e.g., Clarke, 1993; Clarke et al., 1996; Allen et al., 2011), but these particles usually have diameters significantly smaller than 0.1 microns, and must grow via coagulation and gas-phase condensation in the boundary layer before they activate into cloud droplets. Because we cannot accurately represent this process with a single mode, we short-circuit it, specifying a free-tropospheric $N_{\text {a }}$ comparable to measured CCN concentrations but choosing these particles to already have a mean size of 0.1 micron and $\sigma_{\mathrm{g}}=2$, similar to what we assume for the refitted surface aerosol source. We neglect the surface source of dimethyl 
sulfide gas that helps free-tropospheric aerosols grow into the accumulation-mode size range. Functionally, this is tantamount to assuming entrained aerosols instantaneously grow to this mean size by coagulation and gas-phase condensation when they enter the boundary layer, a process which in reality may take hours to days (Clarke, 1993). This assumption also applies to the contribution to aerosol number concentration from the surface source for smaller particle sizes, which we consider as viable $\mathrm{CCN}$ when refitting the Clarke et al. (2006) parameterization to our single accumulation mode.

Our single mode approach omits a number of physical processes present in the real system, and it is fair to question the impact of these omissions. We are neglecting the radiative effect of aerosols for reasons discussed earlier; hence we have less need to simulate the coarse mode. Since we do not represent the Aitken mode, we do not represent spontaneous nucleation of new aerosol particles, and the growth of a population of small aerosol particles via gas deposition is assumed to be instantaneous. These are potentially important issues, especially in the very clean conditions of POCs, though observations from VOCALS RF06 found little evidence for a strong nucleation source (Wood et al., 2011b). The importance of small particles as a potential CCN source may depend on their timescale for growth into viable $\mathrm{CCN}$ by means of coagulation and chemical deposition, compared to the boundary layer overturning timescale. If scavenging processes are active and overturning is fast, many small particles will be removed through cloud processing before reaching CCN sizes. In POCs, where the boundary layer is decoupled and the overturning time is much longer, growth of Aitken mode particles may be a more efficient contributor to the $\mathrm{CCN}$ budget. More in-depth consideration of these effects is beyond the scope of this paper but has been addressed to some extent (for timescales on the order of a day) in Kazil et al. (2011). Despite its simplifications, the single-mode approximation captures several important aerosol-cloud interaction processes, as we will see, and its simplicity and efficiency make it especially attractive for more idealized simulations.

The full system of equations governing the bulk aerosol moments in each grid cell are

$$
\begin{aligned}
\frac{\mathrm{d} N_{\mathrm{ad}}}{\mathrm{d} t} & =\left.\frac{\mathrm{d} N_{\mathrm{ad}}}{\mathrm{d} t}\right|_{\mathrm{Srf}}-\left.\frac{\mathrm{d} N_{\mathrm{ad}}}{\mathrm{d} t}\right|_{\mathrm{Act}}-\left.\frac{\mathrm{d} N_{\mathrm{ad}}}{\mathrm{d} t}\right|_{\mathrm{ScvCld}}-\left.\frac{\mathrm{d} N_{\mathrm{ad}}}{\mathrm{d} t}\right|_{\mathrm{ScvRn}} \\
& +\left.\frac{\mathrm{d} N_{\mathrm{d}}}{\mathrm{d} t}\right|_{\text {Evap }}+\left.\frac{\mathrm{d} N_{\mathrm{r}}}{\mathrm{d} t}\right|_{\text {Evap }}+\left.\frac{\mathrm{d} N_{\mathrm{ad}}}{\mathrm{d} t}\right|_{\mathrm{NMT}}
\end{aligned}
$$

$$
\begin{aligned}
\frac{\mathrm{d} N_{\mathrm{d}}}{\mathrm{d} t} & =\left.\frac{\mathrm{d} N_{\mathrm{ad}}}{\mathrm{d} t}\right|_{\text {Act }}-\left.\frac{\mathrm{d} N_{\mathrm{d}}}{\mathrm{d} t}\right|_{\text {Auto }}-\left.\frac{\mathrm{d} N_{\mathrm{d}}}{\mathrm{d} t}\right|_{\text {Accr }}-\left.\frac{\mathrm{d} N_{\mathrm{d}}}{\mathrm{d} t}\right|_{\text {Evap }} \\
& +\left.\frac{\mathrm{d} N_{\mathrm{d}}}{\mathrm{d} t}\right|_{\text {NMT }}
\end{aligned}
$$

$$
\begin{aligned}
\frac{\mathrm{d} N_{\mathrm{r}}}{\mathrm{d} t} & =\left.\frac{\mathrm{d} N_{\mathrm{d}}}{\mathrm{d} t}\right|_{\text {Auto }}-\left.\frac{\mathrm{d} N_{\mathrm{r}}}{\mathrm{d} t}\right|_{\text {SlfC }}-\left.\frac{\mathrm{d} N_{\mathrm{r}}}{\mathrm{d} t}\right|_{\text {Evap }}-\left.\frac{\mathrm{d} N_{\mathrm{r}}}{\mathrm{d} t}\right|_{\text {Fallout }} \\
& +\left.\frac{\mathrm{d} N_{\mathrm{r}}}{\mathrm{d} t}\right|_{\mathrm{NMT}}
\end{aligned}
$$

$$
\begin{aligned}
\frac{\mathrm{d} q_{\mathrm{ad}}}{\mathrm{d} t} & =\left.\frac{\mathrm{d} q_{\mathrm{ad}}}{\mathrm{d} t}\right|_{\mathrm{Srf}}-\left.\frac{\mathrm{d} q_{\mathrm{ad}}}{\mathrm{d} t}\right|_{\mathrm{Act}}-\left.\frac{\mathrm{d} q_{\mathrm{ad}}}{\mathrm{d} t}\right|_{\mathrm{ScvCld}}-\left.\frac{\mathrm{d} q_{\mathrm{ad}}}{\mathrm{d} t}\right|_{\mathrm{ScvRn}} \\
& +\left.\frac{\mathrm{d} q_{\mathrm{aw}}}{\mathrm{d} t}\right|_{\text {Evap }}+\left.\frac{\mathrm{d} q_{\mathrm{ar}}}{\mathrm{d} t}\right|_{\text {Evap }}+\left.\frac{\mathrm{d} q_{\mathrm{ad}}}{\mathrm{d} t}\right|_{\mathrm{NMT}}
\end{aligned}
$$

$$
\begin{aligned}
\frac{\mathrm{d} q_{\mathrm{aw}}}{\mathrm{d} t} & =\left.\frac{\mathrm{d} q_{\mathrm{ad}}}{\mathrm{d} t}\right|_{\text {Act }}+\left.\frac{\mathrm{d} q_{\mathrm{ad}}}{\mathrm{d} t}\right|_{\mathrm{ScvCld}}-\left.\frac{\mathrm{d} q_{\mathrm{aw}}}{\mathrm{d} t}\right|_{\text {Auto }}-\left.\frac{\mathrm{d} q_{\mathrm{aw}}}{\mathrm{d} t}\right|_{\text {Accr }} \\
& -\left.\frac{\mathrm{d} q_{\mathrm{aw}}}{\mathrm{d} t}\right|_{\text {Evap }}+\left.\frac{\mathrm{d} q_{\mathrm{aw}}}{\mathrm{d} t}\right|_{\mathrm{NMT}}
\end{aligned}
$$

$$
\begin{aligned}
\frac{\mathrm{d} q_{\mathrm{ar}}}{\mathrm{d} t} & =\left.\frac{\mathrm{d} q_{\mathrm{aw}}}{\mathrm{d} t}\right|_{\text {Auto }}+\left.\frac{\mathrm{d} q_{\mathrm{aw}}}{\mathrm{d} t}\right|_{\text {Accr }}+\left.\frac{\mathrm{d} q_{\mathrm{ad}}}{\mathrm{d} t}\right|_{\mathrm{ScvRn}}-\left.\frac{\mathrm{d} q_{\mathrm{ar}}}{\mathrm{d} t}\right|_{\text {Evap }} \\
& -\left.\frac{\mathrm{d} q_{\mathrm{ar}}}{\mathrm{d} t}\right|_{\text {Fallout }}+\left.\frac{\mathrm{d} q_{\mathrm{ar}}}{\mathrm{d} t}\right|_{\mathrm{NMT}} .
\end{aligned}
$$

Here subscript Srf denotes a surface flux, Act is CCN activation, ScvCld is interstitial scavenging by cloud droplets, ScvRn is interstitial scavenging by rain droplets, Evap is evaporation, Auto is autoconversion (collisions between cloud droplets yielding a droplet larger than $25 \mu \mathrm{m}$ radius, the cutoff radius for the cloud mode), Accr is accretion, SlfC is self-collection of rain, and NMT are non-microphysical terms (advection, large-scale subsidence, and sub-grid turbulent mixing).

The equations for $N_{\mathrm{d}}$ and $N_{\mathrm{r}}$ are identical to the standard formulations within version 3 of the Morrison microphysics implemented in SAM v6.9, though the aerosol mass and number used within the Abdul-Razzak and Ghan activation parameterization are now the local values of $q_{\mathrm{a}}=q_{\mathrm{ad}}+q_{\mathrm{aw}}$ and $N_{\text {ad }}+N_{\mathrm{d}}$, respectively. The equation for $N_{\text {ad }}$ also includes cloud and rain evaporation terms from the Morrison schemes, as well as contributions from the surface flux, interstitial scavenging, and advection/turbulence. The microphysical mass sources and sinks are derived from the corresponding Morrison cloud and rain mass sources and sinks using the Ivanova-Leighton approximations (1) and (2). One modification was made to the Morrison scheme. The default scheme assumes no loss of cloud droplet number due 
to evaporation until all water is removed from a grid box (homogeneous mixing). This assumption has been replaced with the heterogeneous mixing assumption that cloud number is evaporated proportionately to cloud water mass, which theory and field measurements suggest may be more appropriate for stratocumulus clouds (Baker et al., 1984; Burnet and Brenguier, 2007).

The discretized system preserves aerosol mass and number budgets within the domain. The domain-integrated mass source and sink terms are due to surface flux of $q_{\text {ad }}$, fall out of $q_{\mathrm{ar}}$, and mean vertical advection. Aerosol number has a more complex budget. One unforeseen complication was the limiter tendencies within the Morrison microphysics code necessary to prevent unphysical rain and cloud droplet size distributions. To conserve mass, the Morrison scheme adds or subtracts rain and cloud number to keep the droplet size distributions within observationally derived bounds. We maintain a closed aerosol budget under these conditions by shifting aerosol number between $N_{\mathrm{r}}$ or $N_{\mathrm{d}}$ and $N_{\mathrm{ad}}$. A spurious source of total number (which we track as a term in the aerosol budget) can still result from the rare case when the required droplet number source exceeds the available dry aerosol number. This occurs in our simulations only when the boundary layer is extremely aerosol depleted, and this spurious source is small relative to the surface source.

\subsection{Model domain, grid resolution, and boundary conditions}

Most of the simulations were run in two dimensions, as the computational expense of multiple 10-20 day runs was unaffordable in 3-D with readily available resources. In Sect. 5.1, we compare the behavior of identically forced 2-D and 3-D cases. Except where otherwise noted, 2-D runs use a $24 \mathrm{~km}$ wide periodic domain with $125 \mathrm{~m}$ horizontal resolution and 192 horizontal grid points, and a stretched vertical grid of 384 grid points, with spacing varying from $30 \mathrm{~m}$ at the surface to $5 \mathrm{~m}$ in a layer from $200 \mathrm{~m}$ to $1500 \mathrm{~m}$, then stretching to the domain top at $30 \mathrm{~km}$ (necessary for radiation). One domain-size sensitivity study uses a $96 \mathrm{~km}$ wide domain, and the POC runs discussed in Sect. 8 extend the 2$\mathrm{D}$ grid to $192 \mathrm{~km}$ in width. The 3-D sensitivity study uses a $24 \mathrm{~km} \times 24 \mathrm{~km}$ doubly-periodic domain. A dynamical time step of $0.5 \mathrm{~s}$ is used in all cases, adaptively shortened when necessary to avoid numerical instability (an infrequent occurrence).

\section{Initialization and forcing}

\subsection{Temperature, moisture, and wind}

The thermodynamic sounding and winds used in this study are loosely based on the VOCALS-RF06 derived profiles of Berner et al. (2011), with the same specified SST of $291.15 \mathrm{~K}$. Changes include a reduction of the inversion
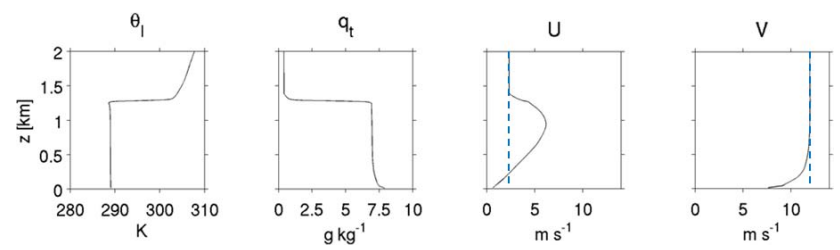

Fig. 3. Basic thermodynamic sounding and wind profiles used for all simulations. Dashed blue lines show the geostrophic wind, which is constant with height. Domain average over hours 3-4 of run W6.5/NA100 depicted.

height to $1300 \mathrm{~m}$ from $1400 \mathrm{~m}$ and initial boundary layer $q_{\mathrm{t}}$ reduced to $7.0 \mathrm{~g} \mathrm{~kg}^{-1}$ from $7.5 \mathrm{~g} \mathrm{~kg}^{-1}$. This results in a thinner and less drizzly initial cloud layer that does not deplete a large fraction of the initial aerosol during the spin-up of the simulations. The wind is forced using a vertically uniform geostrophic pressure gradient and the initial sounding is tuned to minimize inertial oscillations. Maintaining steady FT temperature and moisture profiles is necessary for our purposes, since these are part of the steady boundary forcing that allows the boundary layer to possibly reach a steady state. To prevent slow drifts of the FT conditions due to imbalance between subsidence warming/drying and radiative cooling, the free-tropospheric moisture and temperature are nudged to their initial profiles (or downward linear extrapolations thereof, if the inversion shallows more than $150 \mathrm{~m}$ from its initial specification) on a one hour timescale in a layer beginning $150 \mathrm{~m}$ above the diagnosed inversion height. Experience has shown that providing $150 \mathrm{~m}$ of buffer between the diagnosed inversion top and nudging layer is sufficient to avoid disrupting the model circulation. The sounding and winds averaged over hour three of the control case are depicted in Fig. 3. Slight random noise in the initial temperature field is used to initiate eddy motions.

\subsection{Radiation}

Most simulations use diurnally averaged insolation and an insolation-weighted solar zenith angle appropriate for the latitude and time of year of the VOCALS-RF06 POC observation. Section 6.2 presents a sensitivity study using a diurnal cycle of insolation.

\subsection{Subsidence}

Mean subsidence is assumed to increase linearly from the surface to a height of $3000 \mathrm{~m}$ and to be constant above that. Throughout this paper, the subsidence profile is indicated using its value at a height of $1500 \mathrm{~m}$, which is between 5.0 $6.5 \mathrm{~mm} \mathrm{~s}^{-1}$ in the simulations presented. These values are somewhat larger than our best guess of the actual mean subsidence at $1500 \mathrm{~m}$ during VOCALS-RF06 $\left(2 \mathrm{~mm} \mathrm{~s}^{-1}\right.$; Wood et al., 2011b); the observed inversion was deepening during the previous day (Wood et al., 2011b) so we would not expect the 
Table 1. List of runs performed in this study. Run names concatenate the large-scale subsidence forcing $\mathrm{W}$ at $1500 \mathrm{~m}$ given in $\mathrm{mm} \mathrm{s}^{-1}$, followed by initial PBL aerosol concentration NA in $\# \mathrm{mg}^{-1}$, followed by any other modifiers for sensitivity studies. All runs use identical thermodynamic initialization, a FT aerosol concentration of $100 \mathrm{mg}^{-1}$ and a $24 \mathrm{~km}$ horizontal domain size, except where noted. POC runs are $192 \mathrm{~km}$ wide and are initialized with equally sized regions of higher and lower aerosol concentration given by the two numbers after NA.

\begin{tabular}{ll}
\hline Run & Notes \\
\hline W5/NA100 & Evolution through multiple regimes. \\
W5/NA100/3-D & 3-D version of W5/NA100; collapses to shallow, clean, drizzling equilibrium. \\
W6.5/NA100 & Increased subsidence; results in stable, well-mixed Sc equilibrium. \\
W5/NA100/LD & Larger 96 km wide domain, behaves identically to W5/NA100. \\
W5/NA100/DC & Diurnal cycle of insolation; evolution similar to W5/NA100 with diurnal modulation \\
W6.5/NA100-0FT & Run varying FT aerosol; entrainment dilution dominates surface source \\
W[5-6.5]/NA100/[DC] & Series varying subsidence, with and without diurnal cycle. \\
W6.5/NA[10-90]/Z[500-1700] & Series varying initial PBL aerosol and inversion height. \\
W5/NA30:25-POC & Large domain run with horizontal aerosol gradient, entire domain experiences cumuliform transition. \\
W5/NA60:40-POC & Large domain run with horizontal aerosol gradient, entire domain experiences cumuliform transition. \\
W5/NA100:50-POC & Large domain run with horizontal aerosol gradient, low $N_{\text {a region transitions to form long-lived POC. }}$ \\
\hline
\end{tabular}

observed subsidence to yield a steady-state boundary layer structure. Our chosen subsidence range exhibits an interesting set of aerosol-cloud-precipitation interactions and longlived regimes under steady forcing. A simulation with the observed subsidence produces an initial evolution qualitatively similar to the first case discussed below, but with more rapid initial cloud deepening and onset of drizzle. In the VOCALS study region, there is a significant diurnal cycle of subsidence, but we have not included it here for simplicity, since in this paper our focus is on cloud-aerosol regimes which evolve mainly in response to the average forcing over longer periods of time.

\subsection{Microphysics}

Throughout this paper, aerosol concentrations are presented in units of number per milligram of dry air $\left(\# \mathrm{mg}^{-1}\right)$; this quantity is conserved in motions through a well-mixed layer, whereas the more typical unit of $\mathrm{cm}^{-3}$ is not. Conveniently, the units are approximately equivalent at $850 \mathrm{mb}$. The aerosol number concentration in the FT is set to $100 \mathrm{mg}^{-1}$, typical of FT CCN concentrations over the remote ocean observed in VOCALS (Allen et al., 2011). A sensitivity test with no FT aerosol is discussed in Sec. 6.1. Within the MBL, cases with vertically uniform initial aerosol concentrations ranging from $100 \mathrm{mg}^{-1}$ to as low as $10 \mathrm{mg}^{-1}$ are considered, inspired by VOCALS-observed ranges within the MBL over the remote ocean (Allen et al., 2011).

\section{Simulations}

Table 1 lists the simulations discussed in this paper and summarizes our naming convention. Our selection of runs explores a variety of different aerosol-cloud-precipitation feedbacks on long timescales (up to 20 days) under constant forcing. Homogeneous runs in a small ( $24 \mathrm{~km}$ wide) domain allow the characterization of aerosol-cloud regimes, longlived states with characteristic aerosol budget balances and cloud-precipitation statistics, as well as regime transitions; interactions between regimes are explored in larger domain (192 km wide) POC runs.

The model behavior agrees qualitatively with observations in a number of important respects that increase our confidence in its applicability. In the model, stable stratocumulus decks can persist with diurnally averaged LWPs up to around $120 \mathrm{~g} \mathrm{~m}^{-2}$, but larger LWPs result in precipitation sinks of aerosols that cannot be balanced by reasonable source strengths. This agrees well with the LWP climatology of Wood and Hartmann (2006) for subtropical stratocumulus. The modeled transition from stratocumulus to open cells occurs via strong precipitation feedbacks, again in agreement with observations (van Zanten and Stevens, 2005; Comstock et al., 2005; Wood et al., 2011b), and in an observationally reasonable period on the order of ten hours; in the VOCALS campaign, POCs were observed to form rapidly, almost always in the pre-dawn, early morning hours when LWP reaches its maximum (Wood et al., 2011b, 2008). The model also produces a post-transition vertical structure of aerosol in good agreement with observations, with a surface layer $N_{\text {ad }}$ on the order of $20-30 \mathrm{mg}^{-1}$ and a decoupled upper layer with much lower values, including an "ultra-clean layer" as observed in VOCALS RF06 (Wood et al., 2011b).

\section{Evolution through multiple cloud-aerosol regimes}

We begin our analysis with run W5/NA100. Figure 4 depicts time-height plots of horizontally averaged total (dry plus wet) aerosol number concentration and liquid water content, as well as time series for important domain-averaged MBL meteorological variables and for individual tendency terms from the budget equation for MBL-averaged aerosol number 


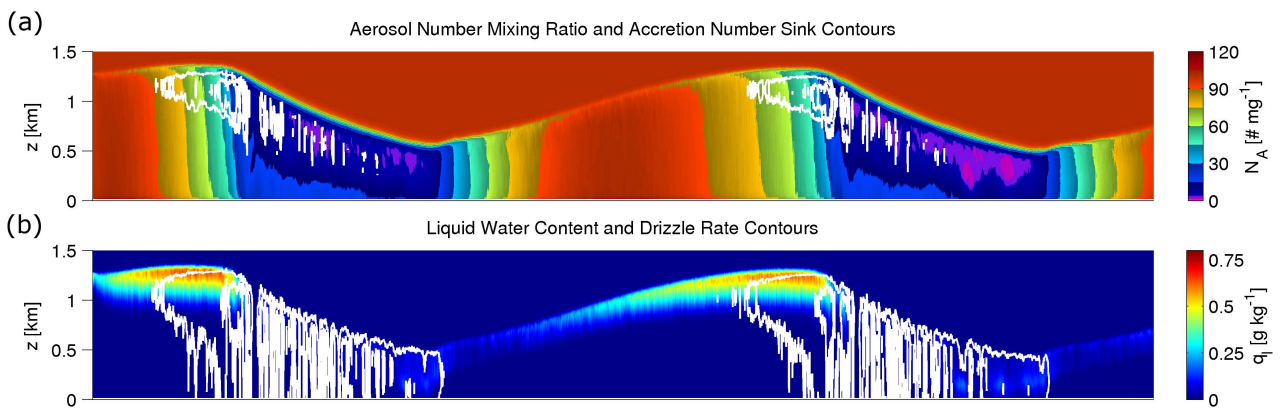

(c)
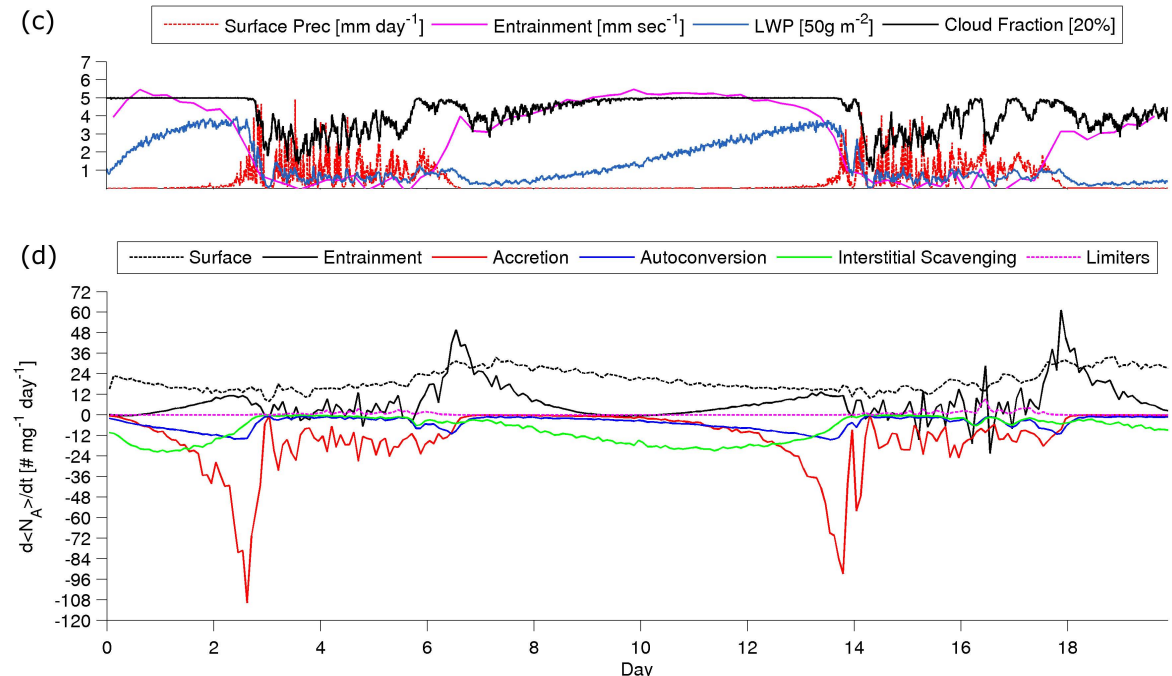

Fig. 4. Time-height plots and time series for run W5/NA100. (a) Total aerosol number concentration $N_{\mathrm{a}}$ with contours $\left[75225 \mathrm{mg}^{-1} \mathrm{day}^{-1}\right.$ ] of accretion number sink $\left.\frac{\mathrm{d} N_{\mathrm{d}}}{\mathrm{d} t}\right|_{\text {Accr }}$. (b) Liquid water content $q_{1}$ and contours of drizzle flux [0.2 2.0 mm day $^{-1}$ ]. (c) Domain-averaged surface precipitation, entrainment, liquid water path, and cloud fraction. (d) MBL averaged aerosol budget tendencies.

$\left\langle N_{\mathrm{a}}\right\rangle$, where angle brackets denote a mass-weighted vertical mean between the surface and the time-varying horizontalmean inversion height $z_{\mathrm{i}}$, determined as the height at which the domain-mean relative humidity goes below $50 \%$. The entrainment source is $w_{\mathrm{e}}\left(N_{\mathrm{aFT}}-\left\langle N_{\mathrm{a}}\right\rangle\right) / z_{\mathrm{i}}$. Here $w_{\mathrm{e}}$ is the entrainment rate, diagnosed from the difference between the $z_{\mathrm{i}}$ tendency and the mean vertical motion at the inversion height. This approach is approximate, but the residual that it induces in the aerosol number budget is only a few percent of the dominant terms. The scavenging of interstitial aerosol number by rain is not shown on the aerosol number budget plot because it never exceeds $1 \mathrm{mg}^{-1}$ day $^{-1}$, which is much smaller than the terms shown. The plots reveal two distinct regimes: a well-mixed, stratocumulus-topped boundary layer with high entrainment, high aerosol and negligible precipitation (days 0-2, 7-13, 18-20), and a cumulus-coupled state with reduced cloud cover, low entrainment, low aerosol, and substantial surface drizzle (days 3-6, 14-17).

Over the first two days, the inversion slowly deepens, the stratocumulus layer thickens, and its LWP increases. There is a $25 \%$ decrease in $\left\langle N_{\mathrm{a}}\right\rangle$ despite negligible surface precipitation. Figure $4 d$ shows that over the first day, the domi- nant aerosol loss term is interstitial scavenging by cloud, with smaller and roughly comparable losses from autoconversion and accretion. These losses are partially offset by the surface source, with a smaller but slowly increasing contribution from entrainment. As noted by Mechem et al. (2006), the FT may act as a reservoir for MBL aerosol when the MBL-average aerosol number concentration falls below that of the FT. During the second day, accretion losses begin to rise more sharply, while interstitial scavenging by cloud diminishes. This occurs due to the improved collection efficiency of drizzle drops for constant $q_{\mathrm{r}}$ and diminishing $N_{\mathrm{r}}$, while interstitial scavenging becomes less efficient as cloud droplets grow larger.

During day 3, accretion losses grow to dominate the number budget. Figure $4 \mathrm{c}$ shows entrainment sharply declining as the domain-averaged surface precipitation rate climbs above $0.5 \mathrm{~mm} \mathrm{day}^{-1}$. This is an example of what Feingold and Kreidenweis (2002) called a "runaway precipitation process", and behavior is quite similar to the transition in the 3-D simulations of Kazil et al. (2011). The decrease in entrainment is due to a rapid decrease in turbulence near the top of the boundary layer, because of drizzle-induced stabilization 


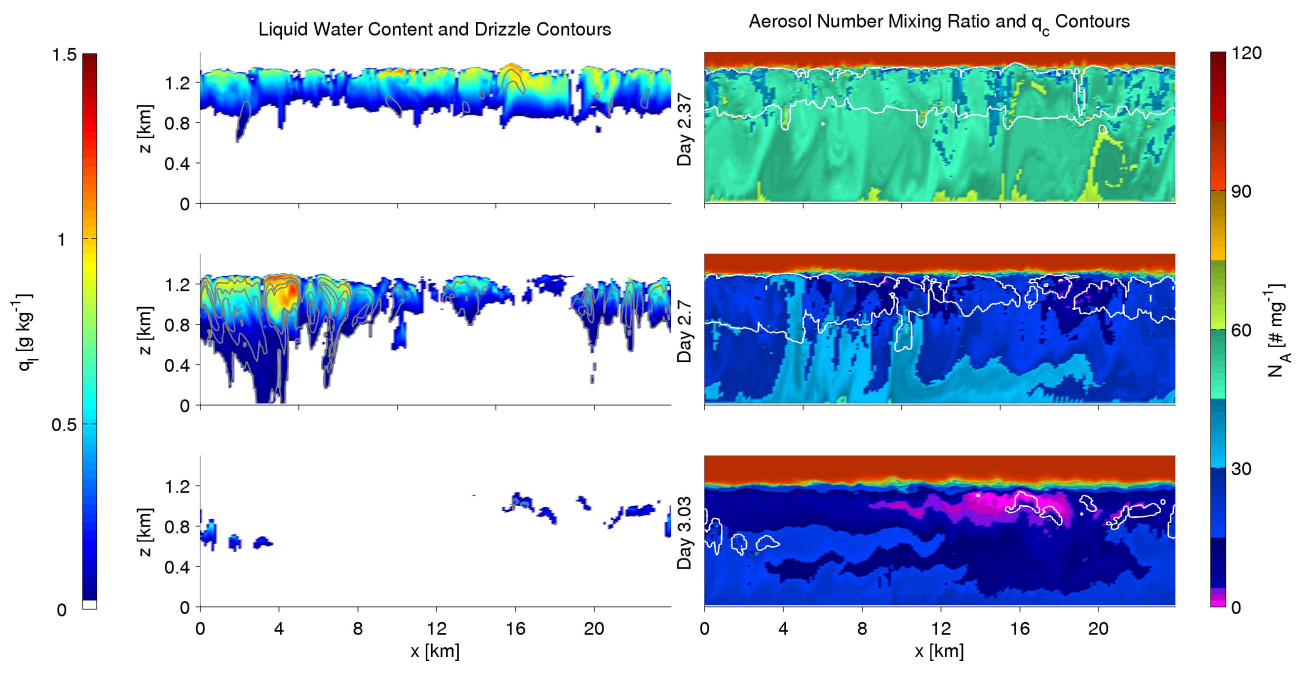

Fig. 5. Left column: $x-z$ cross sections of liquid water content $q_{1}$ with grey contours [0.025 $\left.0.0750 .125 \mathrm{~g} \mathrm{~kg}^{-1}\right]$ of drizzle water mixing ratio $q_{\mathrm{r}}$. Right column: $x-z$ cross sections of total aerosol number concentration $N_{\mathrm{a}}$ with the $0.01 \mathrm{~g} \mathrm{~kg}^{-1}$ of cloud water mixing ratio $q_{\mathrm{c}}$. Each row is separated by approximately $8 \mathrm{~h}$. Note thin region of extremely depleted aerosol in upper MBL in the bottom right panel.

of the boundary layer (Stevens et al., 1998) and reduced destabilization by boundary layer radiative cooling as cloud cover is reduced. The result is a sharp decline of $\left\langle N_{\mathrm{a}}\right\rangle$ and a drastic reduction in LWP. Figure $4 d$ shows the sink terms diminish rapidly at the end of day 3 , primarily because the vast majority of aerosol has been removed from the cloud layer.

The transition from well-mixed stratocumulus to showery, cumuliform dynamics is abrupt. Figure 5 shows $x-z$ snapshots of $q_{1}$ and $N_{\mathrm{a}}$ at three times spanning a sixteen hour period (day 2.37 to day 3.03). At the first time, cloud cover is essentially $100 \%$, with $q_{1}$ maxima near $1 \mathrm{~g} \mathrm{~kg}^{-1}$ and a slight amount of cloud base drizzle under the thickest clouds. Total aerosol concentration $N_{\mathrm{a}}$ has only a slight vertical gradient and is about $60 \mathrm{mg}^{-1}$ in the cloud layer. At the second time, eight hours later, the cloud is thinning and breaking towards the center of the domain, and in a smaller section of the domain there is surface precipitation beneath a strong drizzle cell with cloud-top $q_{1}$ in excess of $1.5 \mathrm{~g} \mathrm{~kg}^{-1}$. The decoupled structure of the boundary layer inhibits aerosol transport from the surface layer into the remaining cloud. Hence, aerosol concentration has become quite vertically stratified, with cloud layer values depleted near or below $15 \mathrm{mg}^{-1}$, except for higher values around the strong updraft of the drizzle cell. At the final time, cloud cover has fallen below $50 \%$; one weak drizzle cell remains, but the cloud layer $q_{1}$ is nearly totally depleted. A narrow band of highly depleted aerosol concentrations sits $100-300 \mathrm{~m}$ below the inversion, with concentrations falling below $5 \mathrm{mg}^{-1}$ (an "ultra-clean layer"), while the surface layer concentrations remain between $15-25 \mathrm{mg}^{-1}$. Referring back to Fig. 4 d, the net MBL aerosol number sink rate during this $16 \mathrm{~h}$ period exceeds $60 \mathrm{mg}^{-1} \mathrm{day}^{-1}$, allowing for near-complete aerosol depletion in less than $24 \mathrm{~h}$.
The showery, cumuliform conditions following the sharp transition from stratocumulus persist for approximately two days. During this period, Fig. $4 \mathrm{c}$ shows that strong drizzle events occur periodically with spikes in surface precipitation up to $4 \mathrm{~mm} \mathrm{day}^{-1}$, cloud cover oscillates around $60-70 \%$ (much of which is optically thin), and domain-mean LWP oscillates between $20-40 \mathrm{~g} \mathrm{~m}^{-2}$. Entrainment is negligible, so mean subsidence continually shallows the boundary layer and the cumulus cloud layer thins. This slow boundary layer collapse is reminiscent of results from a one-dimensional turbulence closure modeling study of Ackerman et al. (1993).

During the sixth day, surface precipitation becomes lighter and more continuous at around $1 \mathrm{~mm} \mathrm{day}^{-1}$ with a reduced vertical gradient of boundary layer aerosol (Fig. 4a), as the cloud layer becomes too shallow to support episodic cumulus showers. The inversion also becomes weaker as it shallows, because the FT is much more stably stratified than the MBL; this promotes entrainment. By day 7, when the inversion has dropped to $600 \mathrm{~m}$ and the MBL is becoming more well-mixed, thin Sc cloud forms near its top and reinvigorates entrainment. The sudden influx of entrained aerosol into the cloud decreases cloud droplet sizes, reducing precipitation efficiency and cloud processing sinks within the boundary layer. This results in a positive entrainment-cloud-aerosol feedback that rapidly replenishes boundary layer aerosol, allowing the layer to sustain radiatively active cloud and begin deepening again via entrainment.

The boundary layer continues to deepen and moisten over the next few days with a similar boundary layer structure. As Sc cloud thickens and aerosol increases, interstitial scavenging increases while the entrainment source decreases due to the decreasing difference between MBL and FT aerosol concentrations. Full cloud cover is achieved during day 9, and by 


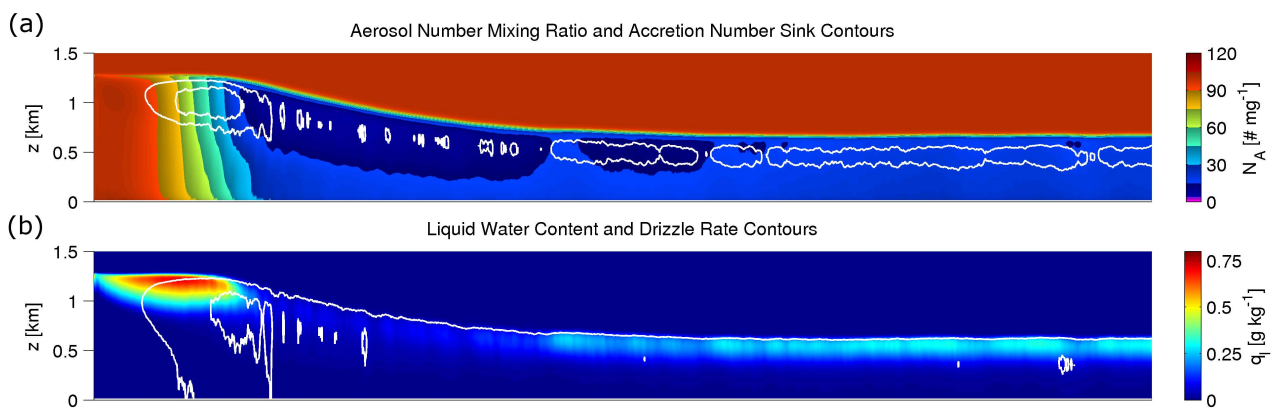

(c)
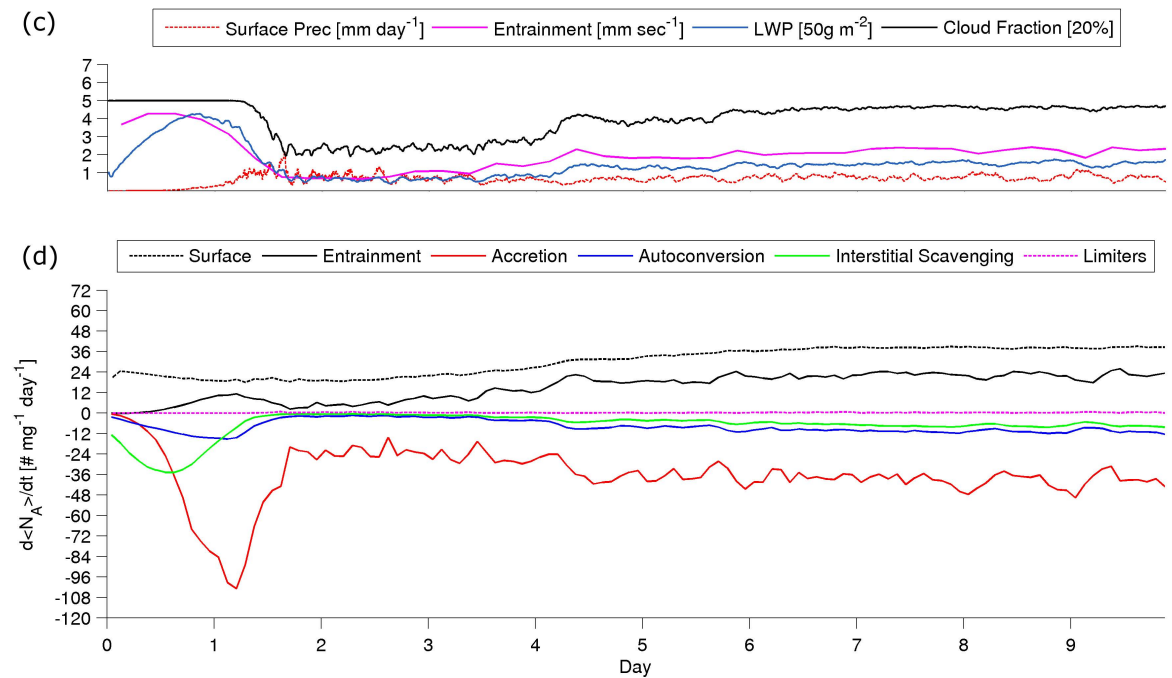

Fig. 6. Time-height plots and time series for run W5/NA100/3-D. Panels as in Fig. 4. Unlike the 2-D case, the time axis only goes to 10 days.

day 10 the aerosol budget roughly resembles that of day 1 . The cloud layer continues to deepen through day 13. At this point, increasing drizzle suppresses entrainment and accretion rapidly depletes aerosol, causing the boundary layer to collapse again; the system exhibits limit cycle behavior. To check domain sensitivity, run W5/NA100/LD (not shown) repeated the simulation in a $96 \mathrm{~km}$ domain. The behavior is quite similar, with boundary layer recovery occurring slightly earlier when inversion depth is $700 \mathrm{~m}$.

\subsection{Comparison with 3-D results}

To check the robustness of our 2-D results, we performed a ten-day, 3-D simulation W5/NA100/3-D identical in forcing and initialization to the W5/NA100 case, except using a domain of $24 \mathrm{~km} \times 24 \mathrm{~km}$ in horizontal extent. The evolution of this run is depicted in Fig. 6. A few differences quickly develop. Entrainment in the 3-D simulation is less efficient than in the 2-D run; the boundary layer first shallows during spin-up, then slowly deepens to a maximum of $1270 \mathrm{~m}$ after one day of evolution; the 2-D run is nearly $50 \mathrm{~m}$ deeper at this time. With less entrainment drying of the boundary layer, the 3-D run achieves a peak LWP exceeding $200 \mathrm{~g} \mathrm{~m}^{-2}$ after one day, as compared to $140 \mathrm{~g} \mathrm{~m}^{-2}$ in the $2-\mathrm{D}$ case at the same time; this accelerates precipitation losses of aerosol in the 3-D case. The cloud interstitial scavenging sink is also nearly twice as large in the 3-D case. One reason for this may be that in 3-D, more of the turbulent kinetic energy is in horizontal motions, keeping air in the stratocumulus layer longer. The combination of these effects accelerates the transition to a collapsing open-cell state in the 3-D case.

While the strengths of the aerosol number source and sink terms differ quantitatively between the 2-D and 3-D configurations, their relative roles are similar. Interstitial scavenging is initially the largest sink of $\left\langle N_{\mathrm{a}}\right\rangle$ and the surface flux the largest source. As multiple processes act to reduce $\left\langle N_{\mathrm{a}}\right\rangle$, the entrainment source strengthens, but is ultimately unable to compete with the accretion losses as drizzle becomes significant. Cloud fraction decreases in both runs following the development of significant surface precipitation and the rainout of $q_{1}$, demonstrating qualitatively similar dynamics.

The initial collapse of the 3-D run through day 3.5 closely resembles that of the 2-D run, though surface precipitation is not nearly as intense at $1-1.5 \mathrm{~mm} \mathrm{day}^{-1}$, more cloud remains near the inversion base, and there is somewhat more entrainment $\left(1 \mathrm{~mm} \mathrm{~s}^{-1}\right)$. As the MBL shallows, the precipitation rate drops and becomes steadier, as in the 2-D run, but unlike in 2-D, at day 3.5, after two days of collapse, the 

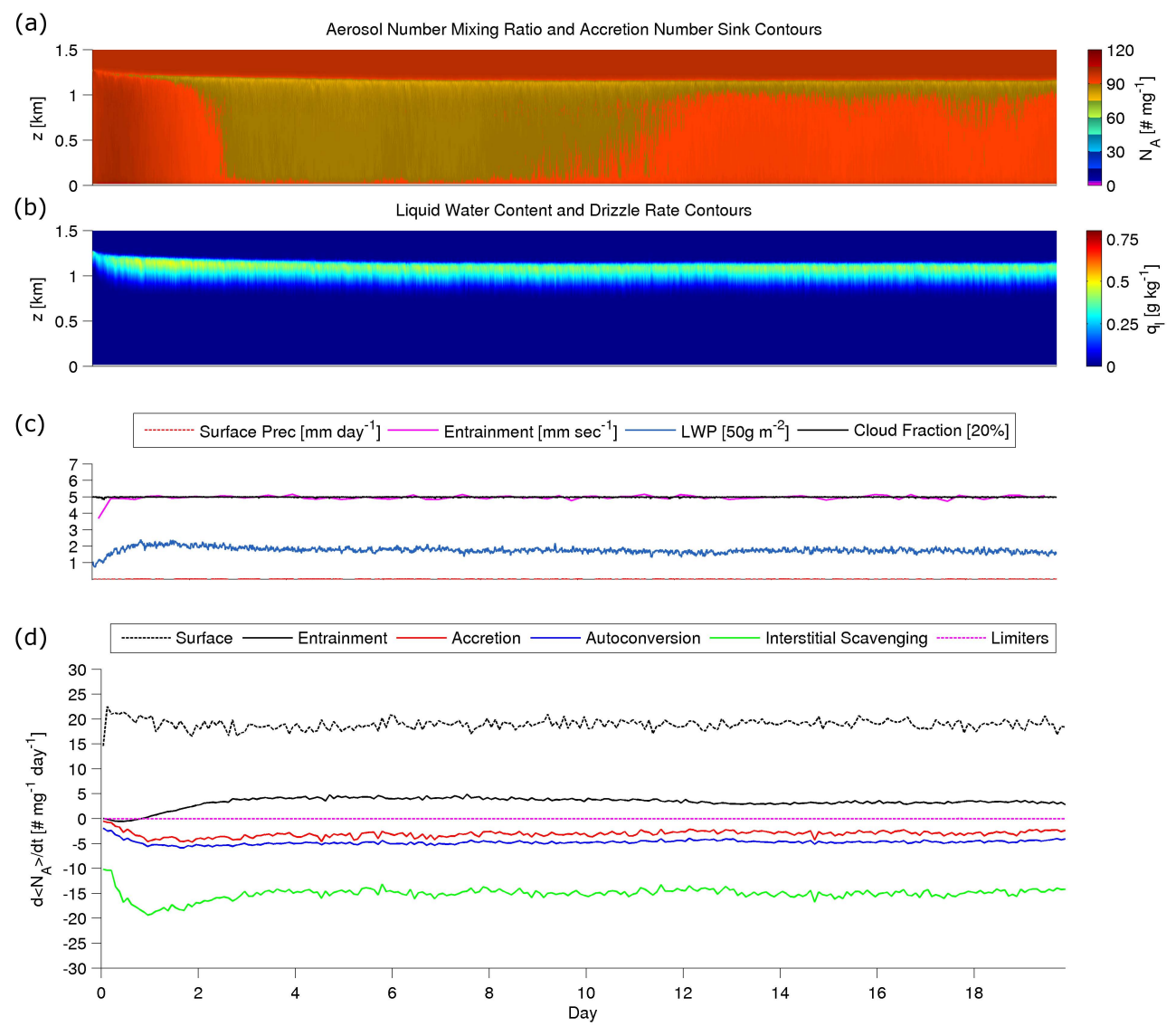

Fig. 7. Time-height plots and time series for run W6.5/NA100. Panels as in Fig. 4.

entrainment rate also starts to rise. Like in 2-D, there is a time just after day 4 at which the stratocumulus LWP suddenly increases as the MBL becomes well-mixed, but this is accompanied by much less entrainment increase than occurs in the 2-D case, because it was already preceded by $50 \%$ stratocumulus cover. Without a sudden increase in aerosol influx, precipitation continues, and in the 3-D run, the MBL settles into a statistically-steady, shallow, clean, precipitating MBL resembling the "clean" equilibrium of Baker and Charlson (1990).

The distinctly different long-term behavior of the 2-D and 3 -D versions of the model suggest that for clean, precipitating boundary layers with a reservoir of potential $\mathrm{CCN}$ in the FT, there is strong sensitivity to the details of simulated entrainment and turbulent structure. As our current simulations have a relatively coarse horizontal resolution of $125 \mathrm{~m}$, turbulence in our models is less well resolved as the MBL becomes shallow; 2-D and 3-D turbulence also have some qualitatively different behaviors. Additionally, Feingold et al. (2010) showed that the dynamics of the precipitating open cells found in the collapsing state are strongly tied to cold pool convergence at the surface, and the essential differences between 2-D and 3-D cold pool interaction are likely important. Nevertheless, there is substantial qualitative and semi- quantitative agreement in the 2-D and 3-D model simulations of the transition between the deepening stratocumulus regime and the collapsing, cumuliform state. Both simulations exhibit two similar cloud regimes and share a common transition mechanism as interpreted through the aerosol budgets. While the 3-D simulation is more physically defensible as a modeling framework, it is also 200 times as computationally expensive to run, and would be even more so if the horizontal resolution were increased. For the purpose of qualitatively illustrating aerosol-cloud-precipitation interactions and approach to equilibrium, for the rest of this paper we accept the errors inherent in the 2-D approach in order to explore a broader range of initial conditions and enable longer simulations.

\section{Stable equilibrium and sensitivity to forcing}

In the W5/NA100 run, cloud breakup occurs when LWP increases enough to induce a runaway-drizzle-aerosol-loss feedback. This suggests that this transition might be suppressed if LWP remains sufficiently low. With this in mind, Case W6.5/NA100 increases $1500 \mathrm{~m}$ subsidence to $6.5 \mathrm{~mm} \mathrm{~s}^{-1}$, limiting LWP by inhibiting the boundary layer 


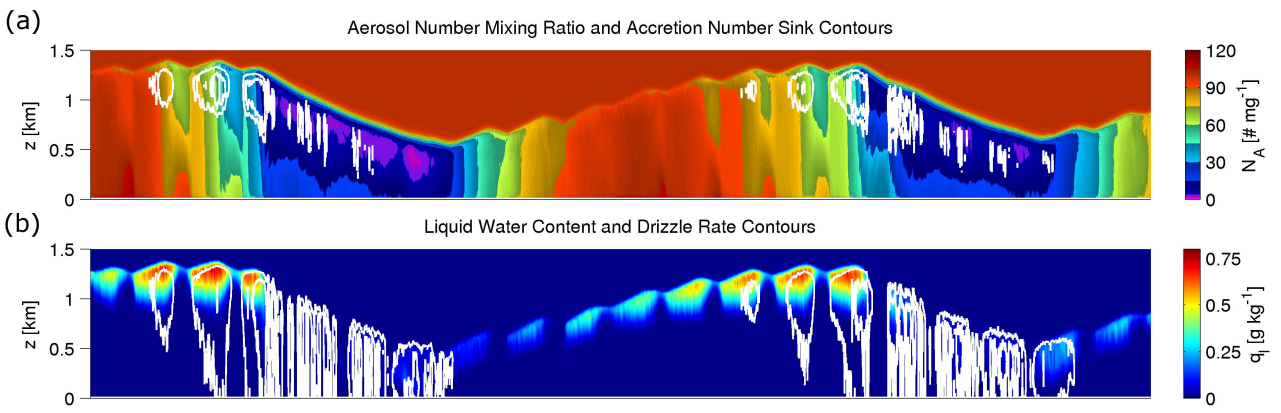

(c)
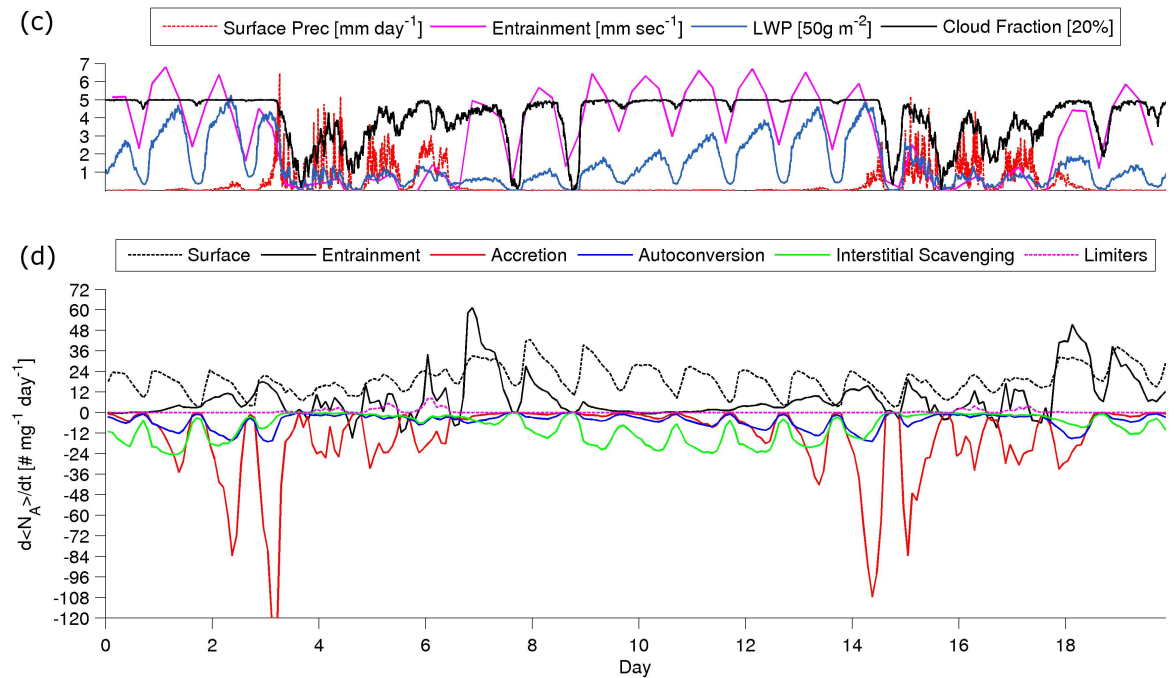

Fig. 8. Time-height plots and time series for run W5/NA100/DC. Panels as in Fig. 4.

from deepening. This case, shown in Fig. 7, reaches a steady, well-mixed, stratocumulus-topped equilibrium state with an inversion height of $1150 \mathrm{~m}$. LWP settles to a mean of approximately $82 \mathrm{~g} \mathrm{~m}^{-2}$ after eight days, with oscillations of $\pm 5 \mathrm{~g} \mathrm{~m}^{-2}$ about this value thereafter. The $\left\langle N_{\mathrm{a}}\right\rangle$ settles around $91 \mathrm{mg}^{-1}$, with $100 \%$ cloud cover, less than $0.1 \mathrm{~mm} \mathrm{day}^{-1}$ of cloud base drizzle and negligible precipitation reaching the surface. The steady state aerosol budget is dominated by an MBL-averaged surface $\left\langle N_{\mathrm{a}}\right\rangle$ source of $20 \mathrm{mg}^{-1} \mathrm{day}^{-1}$ and an interstitial scavenging $\left\langle N_{\mathrm{a}}\right\rangle$ sink of $15 \mathrm{mg}^{-1} \mathrm{day}^{-1}$, with smaller contributions from other processes.

In order to investigate the sensitivity of the stable equilibrium to subsidence, a sweep of identically initialized runs was performed with $1500 \mathrm{~m}$ subsidence varying from $5.0-6.5 \mathrm{~mm} \mathrm{~s}^{-1}$ in increments of $0.25 \mathrm{~mm} \mathrm{~s}^{-1}$. Case W5.75/NA100 took approximately twice as long to collapse as case W5/NA100, but still transitioned to a collapsing regime and exhibited limit cycle behavior. Case W6.0/NA100 arrived at a steady equilibrium with an LWP of $124 \mathrm{~g} \mathrm{~m}^{-2}$ and $\left\langle N_{\mathrm{a}}\right\rangle$ of $61 \mathrm{mg}^{-1}$. Thus a change of $4 \%$ in subsidence produces a totally different long-term character between simulations. The sensitivity of the long-term behavior to this slight change in an external parameter is an indicator of a positive-feedback system (no plots shown).

\subsection{Sensitivity to FT aerosol}

Case W6.5/NA100-0FT is identical to Case W6.5/NA100, except that the FT aerosol concentration is set to zero. In this run, entrainment dilution is always a sink term for $\left\langle N_{\mathrm{a}}\right\rangle$. After a gradual depletion of aerosol, the runaway precipitation sink transitions the system into a collapsing MBL. The simulation was run out to 20 days and remained in a collapsing state, with the inversion continually sinking slowly throughout (no plots shown). The inability of the surface source alone to balance the precipitation sink is noteworthy, illustrating the importance of the FT aerosol source, much as in Mechem et al. (2006). As the surface fluxes of aerosol and moisture have different wind speed dependencies, it is conceivable that in higher wind regimes the surface aerosol flux could dominate precipitation scavenging.

\subsection{Sensitivity to diurnal cycle of insolation}

Case W5/NA100/DC (Fig. 8) is configured similarly to case W5/NA100, except with a diurnal cycle of insolation, and behaves similarly, although the diurnal cycle strongly imprints itself on all boundary layer processes. The transition to a cumuliform MBL, marked by reductions in cloud LWP 


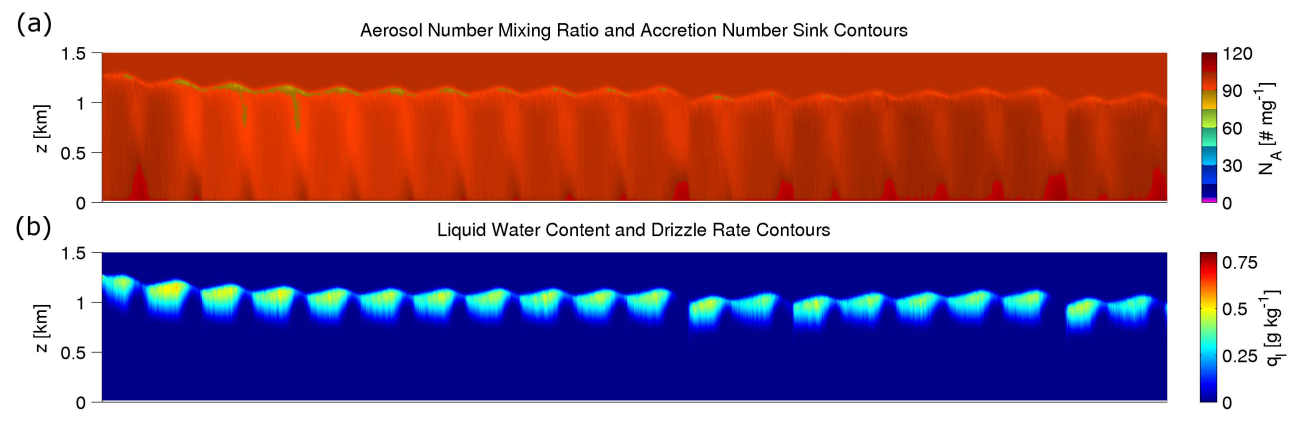

(c)
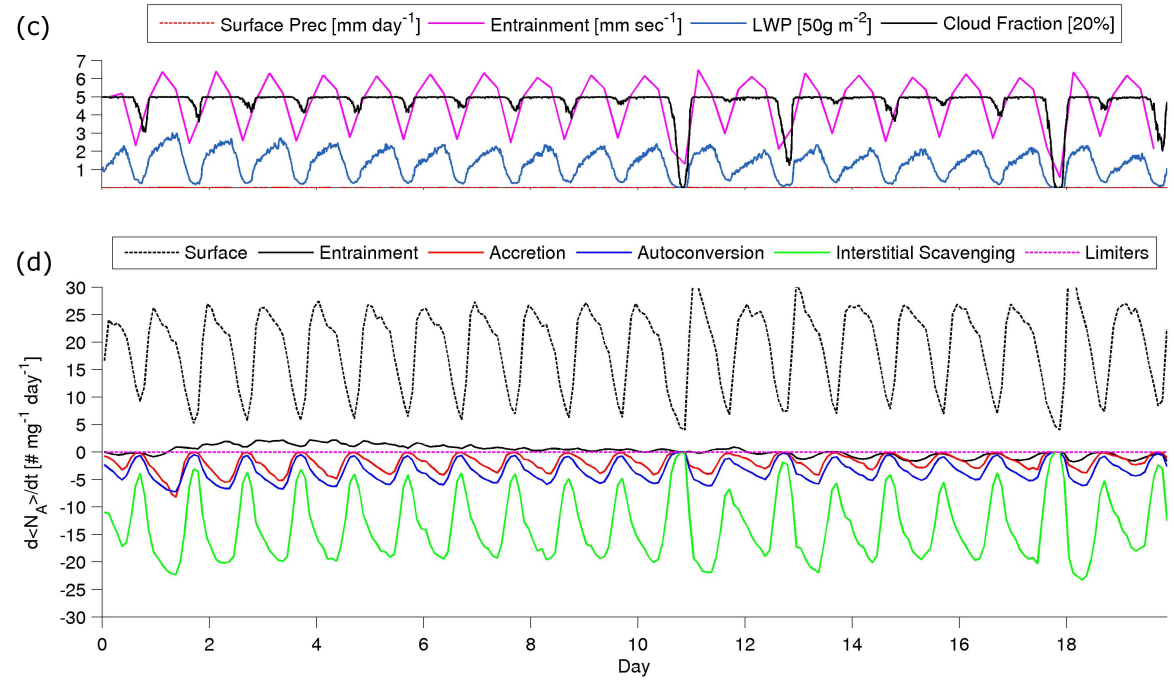

Fig. 9. Time-height plots and time series for run W6.5/NA100/DC. Panels as in Fig. 4.

and cloud fraction, occurs in the early morning of days 3 and 14, when precipitation is most active, as in the formation of observed POCs (Wood et al., 2008). A curious feature of the case is a nearly $2 \mathrm{~m} \mathrm{~s}^{-1}$ oscillation in simulated surface wind speed that drives a large simulated diurnal cycle in surface aerosol number flux (which is proportional to the cube of the wind speed). This effect is attributed to reduced downward turbulent mixing of momentum to the surface layer during the daytime. We speculate that our 2-D simulation is artificially amplifying the simulated wind and surface aerosol flux oscillation in a way that a 3-D simulation would not. Observational data show a much weaker diurnal cycle in wind speed of a few tenths of a meter per second (Dai and Deser, 1999); smaller decreases in surface wind speed during the day would allow the surface aerosol flux to better buffer aerosol sink terms, likely shifting the transition boundary towards a deeper cloud layer and higher LWP. The diurnal modulation of the terms in the aerosol number budget does not seem to alter their relative importance in each cloud regime compared to the W5/NA100 run.

In the higher subsidence run (W6.5/NA100/DC, Fig. 9), the same deep stratocumulus equilibrium state is apparent as in the diurnally averaged case. The statistics are somewhat altered by the diurnal cycle due to non-linearities in the cloud and turbulent response; over the last two days of the simulation, average LWP is $60 \mathrm{~g} \mathrm{~m}^{-2}, z_{\mathrm{i}}$ is $1030 \mathrm{~m}$, and mean $N_{\mathrm{a}}$ is $101 \mathrm{mg}^{-1}$. This makes entrainment a net sink (just barely) for boundary layer aerosol, with the surface source balancing all other terms.

\section{A reduced-order phase plane description of the aerosol-cloud system}

Schubert et al. (1979) discussed characteristic timescales on which a stratocumulus-capped mixed layer adjusts to a sudden change in boundary conditions and forcings. They pointed out that there is a quick (few hour) thermodynamic adjustment of the MBL, followed by a slower adjustment timescale (several days) for the MBL depth to adjust into balance with the mean subsidence. Bretherton et al. (2010) elaborated these ideas using both mixed-layer modeling and LES of stratocumulus-capped boundary layers with fixed cloud droplet concentrations. They showed that with fixed boundary conditions, for any initial condition, the MBL evolution converged after thermodynamic adjustment onto a "slow manifold" along which the entire boundary layer thermodynamic and cloud structure was slaved to a single 


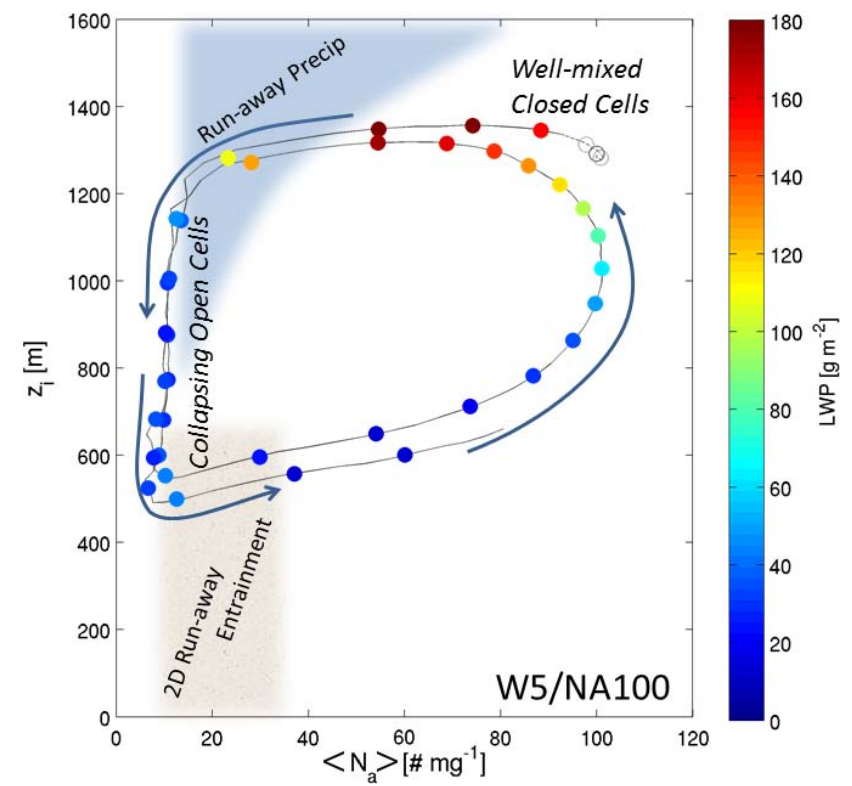

Fig. 10. Phase plane plot for slow evolution of control run W5/NA100. Symbols represent $12 \mathrm{~h}$ box averages and are colored by LWP. Initial condition is showed as an unfilled symbol in black, while first and second $12 \mathrm{~h}$ averages are shown in unfilled light grey, where the vertical profile of cloud and LWP is still undergoing an initial fast adjustment.

slowly-evolving variable, the inversion height $z_{\mathrm{i}}$. With an imposed cloud droplet concentration of $100 \mathrm{~cm}^{-3}$, they found there were two possible slow manifolds: a "decoupled" manifold evolving toward a steady state with small cloud fraction and a shallow inversion, and a "well-mixed" manifold evolving toward a solid stratocumulus layer with a deep inversion. In both equilibria, precipitation was negligible. Simulations initialized with well-mixed boundary layers capped with a cloud layer that was optically thick but non-drizzling converged onto the well-mixed manifold; simulations in which the initial cloud layer was either optically thin or thick and heavily drizzling converged onto the decoupled manifold.

In this section, we explore the use of similar concepts for our cloud-aerosol system. Given the MBL-average aerosol concentration, $\left\langle N_{\mathrm{a}}\right\rangle$, the clouds and turbulence will pattern the aerosol sources and sinks to set up the vertical structure of $N_{\mathrm{a}}$ within the MBL within its turbulent overturning time of tens of minutes (for a coupled boundary layer) to a few hours (for a cumulus-coupled boundary layer). Hence, the combination of $\left\langle N_{\mathrm{a}}\right\rangle$ and $z_{\mathrm{i}}$ provides a reduced-order twodimensional phase space to describe the "slow manifold" evolution of the cloud-aerosol system on timescales of a day or longer.

We start by viewing the W5/NA100 case in this way. Figure 10 shows the position in $\left\langle N_{\mathrm{a}}\right\rangle-z_{\mathrm{i}}$ phase space averaged over sequential $12 \mathrm{~h}$ periods, colored by the LWP during that period. The spacing between successive points indicates how fast a run is evolving. The initial condition is shown with

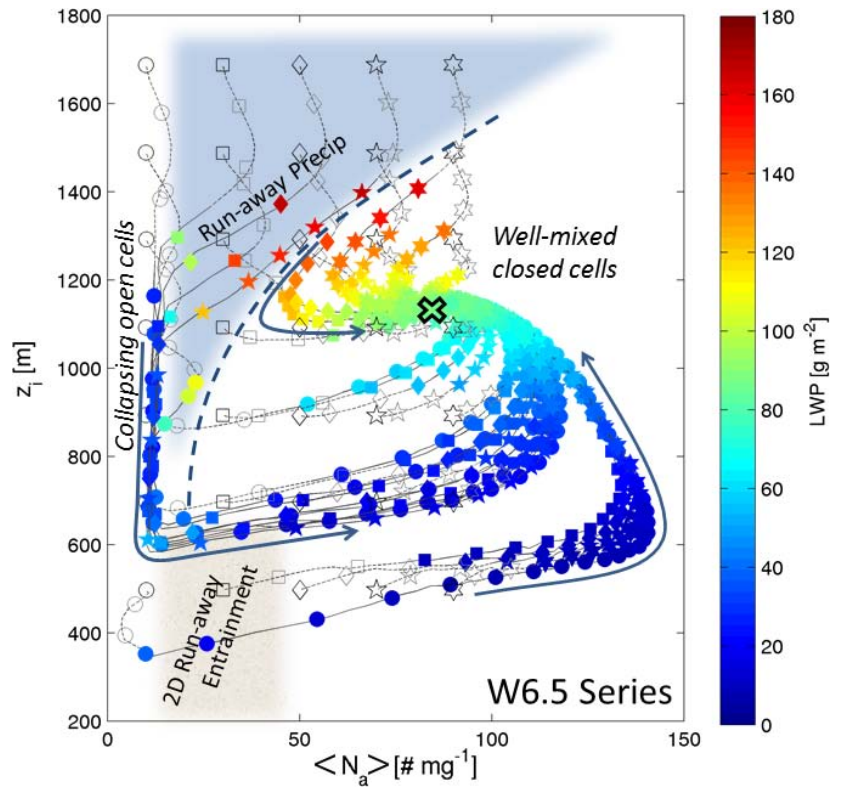

Fig. 11. Phase plane plot like Fig. 10, but for W6.5 cases initialized along a two-dimensional grid of MBL aerosol concentration and inversion height. Different symbols indicate the initial aerosol concentration. Blue dashed line shows the boundary for regime transition under runaway precipitation. The equilibrium is marked by an "x".

a black, unfilled circle, and the first two $12 \mathrm{~h}$ averages are shown using unfilled, grey circles. The circles are connected with a thin dashed line for the first $36 \mathrm{~h}$, after which a thin solid line traces the path of each run.

Different "regimes" through which the system evolves are labeled. Here, a cloud-aerosol regime is defined as a part of phase space with qualitatively similar cloud and aerosol characteristics, and hence a characteristic balance of terms in the aerosol budget. For instance, the open-cell regime is characterized by low aerosol, low LWP, low entrainment and efficient precipitation (accretion) removal of aerosol, while the closed-cell regime is characterized by high aerosol, high LWP, little precipitation, high entrainment, and a balance between cloud scavenging and surface/entrainment aerosol sources. The regimes grade into each other as $\left\langle N_{\mathrm{a}}\right\rangle$ and $z_{\mathrm{i}}$ change; they need not have sharp boundaries in phase space. The shading indicates two regions of phase space in which the aerosol concentration evolves comparatively rapidly, either due to runaway precipitation feedback, or due to rapid "runaway" entrainment of aerosol when the shallow boundary layer with cumuliform convection redevelops thin inversion-base stratocumulus clouds. Overall, the phase space trajectory has converged onto a limit cycle along which it will indefinitely move between the closed-cell and opencell regimes.

To explore the sensitivity of the equilibrium in the W6.5/NA100 case, we performed a grid of identically forced 
runs with the initial MBL aerosol concentration varied from $10-90 \mathrm{mg}^{-1}$ in steps of $20 \mathrm{mg}^{-1}$ and initial inversion heights of $500-1700 \mathrm{~m}$ in steps of $200 \mathrm{~m}$. Initial MBL total water mixing ratio $q_{\mathrm{t}}$ was chosen to yield the same initial cloud depth. Results are plotted on Fig. 11 using the same notation as in Fig. 10; run symbols correspond to the initial aerosol concentration (circle, square, diamond, five-pointed star, sixpointed star for initial aerosol of $10,30,50,70,90 \mathrm{mg}^{-1}$, respectively).

While all runs in the grid ultimately reach the same equilibrium as in the W6.5/NA100 run, there is a clear dichotomy in evolution. After initial thermodynamic adjustment, runs lying above the dashed blue line in phase space will transition into a collapsing MBL via runaway precipitation feedback, while runs below it remain in a well-mixed Sc regime. Arrows show the direction of evolution. Runs that collapse subsequently transition back after the redevelopment of thin stratocumulus near the inversion, as in the W5/NA100 run, rapidly increasing in $\left\langle N_{\mathrm{a}}\right\rangle$ and slowly deepening via entrainment. The shaded transition regions have not shifted despite the changed subsidence, as the aerosol loss rates are not directly affected by the instantaneous mean subsidence.

Unlike Baker and Charlson (1990), we do not find a highaerosol and a low-aerosol equilibrium for the W6.5 series. However, the open-cell regime, which is analogous to their low-aerosol equilibrium, lasts several days. Our 3-D run was for W5, but suggests the possibility of a 3-D low-aerosol steady state for W6.5. Without free-tropospheric aerosol, the runaway-entrainment transition would not occur even in 2-D. Thus, our simulations are consistent in spirit with their hypothesis. Two differences from the idealized aerosol model of Baker and Charlson (1990) are that our interstitial aerosol removal is much more efficient, and we include entrainment dilution that regulates the high-aerosol state to number concentrations of around $100 \mathrm{mg}^{-1}$, about ten times smaller than in their simple model.

Figure 11 is superficially similar to Fig. 5c of Koren and Feingold (2011), which showed the sensitivity of equilibria of a simple "predator-prey" model of cloud-precipitationaerosol interaction to background cloud depth and aerosol concentration, which are external control parameters for that model. The interpretation is completely different, because in Fig. 11 the $\left\langle N_{\mathrm{a}}\right\rangle$ and $z_{\mathrm{i}}$ are internal time-evolving descriptors of the system evolution rather than external parameters; in addition there is a large difference between the studies in the target time and space scales on which the aerosol-cloudprecipitation system is being modeled. However, it is noteworthy that in both studies, there is very rapid loss of cloud and aerosol when the cloud is thick and there is little aerosol, making the system rapidly evolve out of such a regime.

In practice, the stable equilibria of the system are less important than the long-lived regimes and the location of regime transitions in phase space. While the W6.5 series of runs has a single stable equilibrium, real cloud-topped boundary layers advect and also experience weather variabil- ity; in combination, these induce large-scale forcing changes on timescales of days, so equilibria that take a week or more to reach under constant forcing will never be realized. Regime transitions in our model, however, are relatively fast (tens of hours), and under real meteorological conditions, these transitions are relevant, as exemplified by POCs.

\section{POC simulations}

So far, we have considered the evolution of an aerosolcloud system in a small domain through multiple regimes over time, with the possibility of multiple steady states for a given forcing. We now examine the possibility of simultaneously supporting adjacent regions in different aerosol-cloud regimes in an idealized representation of a POC. We extend our domain to $192 \mathrm{~km}$ and specify an initial gradient in aerosol concentration, with a $42 \mathrm{~km}$ region initialized to $\mathrm{N}_{\mathrm{a}}{ }^{+}$, followed by a $12 \mathrm{~km}$ half-sine wave transition to $84 \mathrm{~km}$ initialized at $N_{\mathrm{a}}{ }^{-}$, then another half-sine wave transition back to $42 \mathrm{~km}$ initialized at $\mathrm{Na}_{\mathrm{a}}{ }^{+}$. POC runs are initialized with identical thermodynamic profiles and forcings to the W5/NA100 case. The idea is that the lower $N_{\mathrm{a}}$ cloud within the center of the domain (the incipient POC) will start drizzling and transition via runaway precipitation feedback to open-cell structure. This will reduce entrainment in those regions. Because the inversion height in the open-cell region must stay similar to that in the overcast region, reduced entrainment in part of the domain will slow or reverse inversion deepening over the entire domain, as discussed in Berner et al. (2011). This can prevent the further growth of LWP and hence drizzle in the overcast region, and thereby suppress the transition there, allowing a "coupled slow manifold" behavior hypothesized by Bretherton et al. (2010), in which the open-cell and overcast regions can stably coexist for long periods.

Two pilot runs were tried using $N_{\mathrm{a}}{ }^{+}: N_{\mathrm{a}}{ }^{-}$of $30: 25$ and $60: 40 \mathrm{mg}^{-1}$, but as the simulated stratocumulus cloud layers deepened, the open-cell transition in the $N_{\mathrm{a}}{ }^{-}$region was not complete before the $\mathrm{N}_{\mathrm{a}}{ }^{+}$regions also deepened sufficiently to transition. However, in run W5/NA100:50-POC, initialized with $N_{\mathrm{a}}^{+}: N_{\mathrm{a}}{ }^{-}$of $100: 50 \mathrm{mg}^{-1}$, the open-cell transition in the domain center occurs sufficiently early to reduce the domain-mean $z_{\mathrm{i}}$ and prevent the surrounding overcast region from transitioning. The remainder of this section documents this remarkable behavior.

Figures 12 and 13 show $x-z$ cross sections of $N_{\mathrm{a}}$ and $q_{1}$ at days 0.475 and 1.205. In Fig. 12, the boundary layer is vertically well-mixed in $N_{\mathrm{a}}$ and topped by an overcast stratocumulus layer. No significant drizzle is present, and no strong differences other than the $N_{\mathrm{a}}$ gradient are visible across the domain. Figure 13, $17.5 \mathrm{~h}$ later, shows a picture strongly reminiscent of observations from a POC, with several strong drizzle cells present in the central region and broken cloud. $N_{\mathrm{a}}$ is highly depleted in places, falling below $15 \mathrm{mg}^{-1}$ in the upper layer of the POC, and below $2 \mathrm{mg}^{-1}$ in the bright 

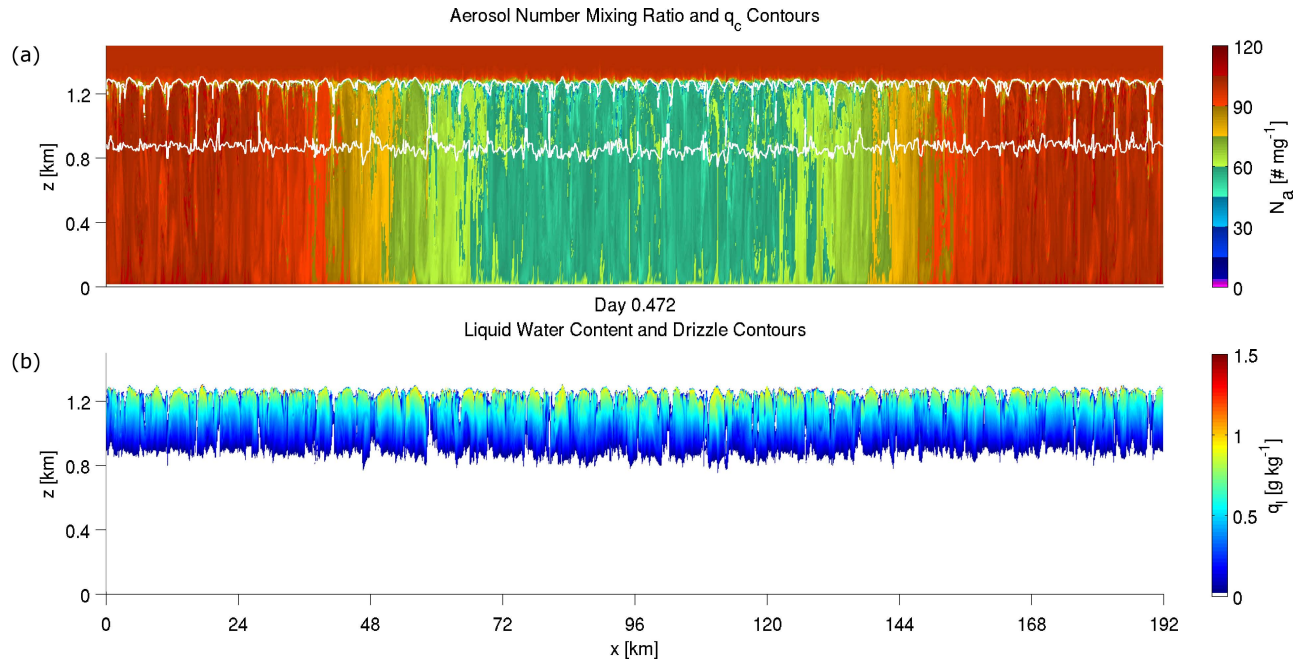

Fig. 12. $x-z$ sections from W5/NA100:50-POC at day 0.47. (a) Aerosol number concentration $N_{\mathrm{a}}$ with the $0.01 \mathrm{~g} \mathrm{~kg}^{-1} q_{\mathrm{c}}$ contour. (b) Liquid water content $q_{1}$ and $[0.025,0.075,0.125] \mathrm{g} \mathrm{kg}^{-1}$ contours of drizzle water mixing ratio $q_{\mathrm{r}}$.

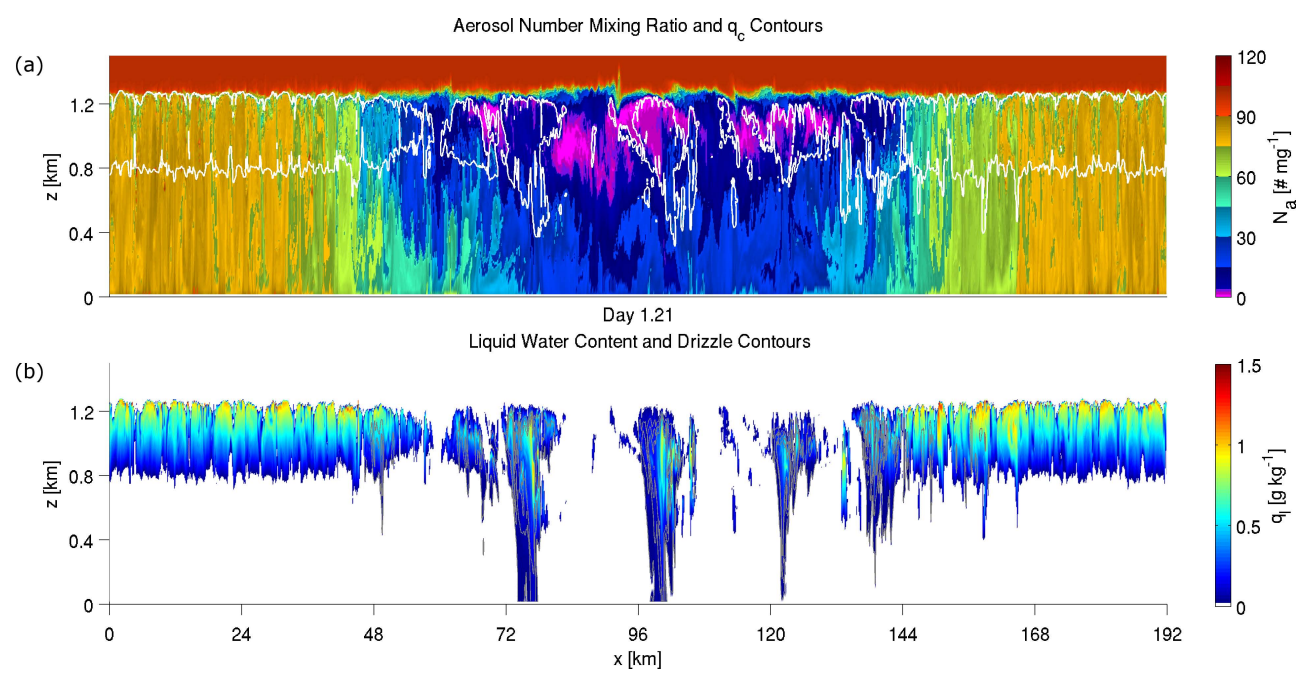

Fig. 13. $x-z$ sections from W5/NA100:50-POC approximately $17.5 \mathrm{~h}$ later at day 1.21. Panels as in Fig. 12. Note the sharpened overall gradient and depletion of $N_{\mathrm{a}}$ in the upper MBL within the POC.

magenta regions, nicely capturing the observed ultra-clean layer (Wood et al., 2011b). The surrounding overcast region maintains full cloud cover without substantial surface precipitation, and $N_{\mathrm{a}}$ remains above $75 \mathrm{mg}^{-1}$ in the majority of the outer region. Another model feature resembling observations of the VOCALS RF06 POC is the location of the horizontal $N_{\text {a }}$ gradient, with the bulk of the aerosol decrease located within the overcast region (Wood et al., 2011b). The qualitative similarity to key features in the observations suggests the simple model captures at least some of the important mechanisms in the real system.

After transition, the POC and overcast regions evolve jointly over the next several days, linked together by circulations acting to maintain an essentially level domain-wide inversion against large differences in entrainment and thermodynamic profiles between the overcast and POC regions. Figure 14 depicts Hovmöller plots of $\left\langle N_{\mathrm{a}}\right\rangle$ and LWP. The spatial evolution of the aerosol and LWP fields in Fig. 14a and $\mathrm{b}$ shows how the POC initially widens rapidly following transition. The different character of the regions is apparent in Fig. 14b, in that the domain maximum and minimum LWP values are contained within the POC, while the overcast region is much more homogeneous. Figure 14a shows the degree to which the aerosol gradient is sharpened and maintained by cloud processing. Interestingly, after its initial expansion, the POC reaches a maximum of $70 \%$ of the domain on day 2.4 , then shrinks back into a quasi-steady equilibrium 

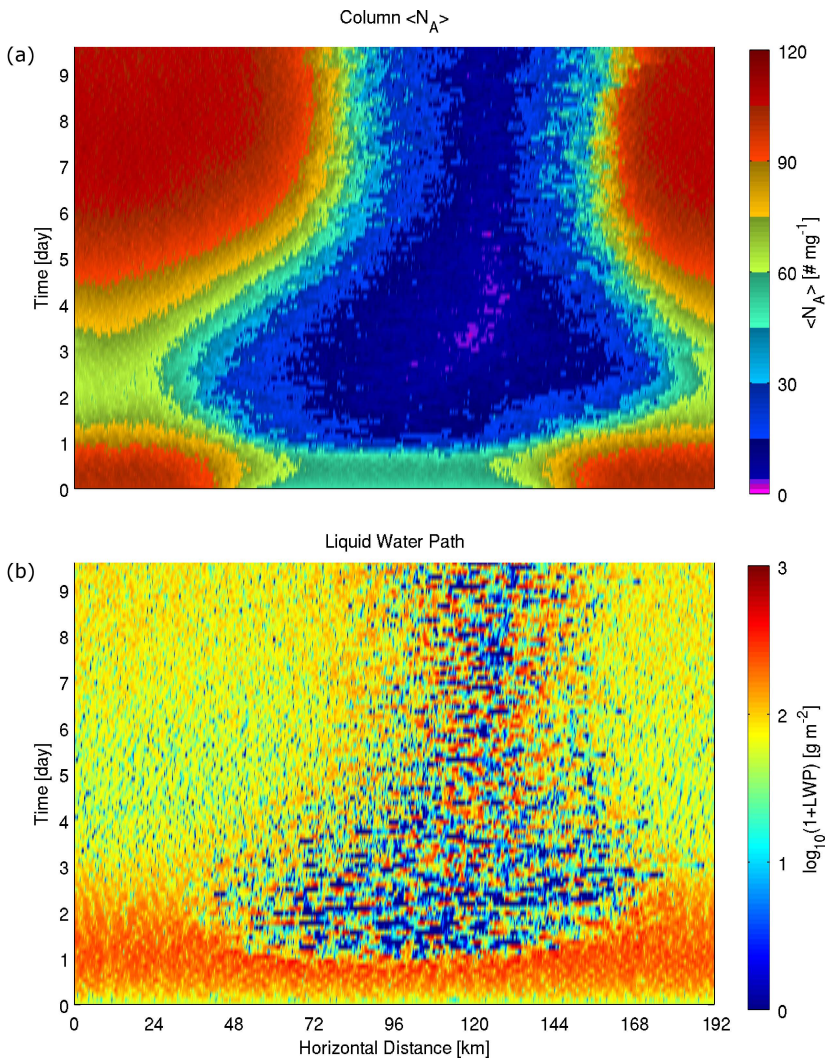

Fig. 14. Hovmöller plots showing evolution of (a) column $\left\langle N_{\mathrm{a}}\right\rangle$ and (b) $\log _{10}$ of $1+$ liquid water path in each column. Note that both minimum and maximum column values for LWP occur within the POC.

with the overcast on day 9 , occupying $25-30 \%$ of the total area.

In order to understand the apparent equilibration, we plot time series of several variables from averages over $24 \mathrm{~km}$ wide stripes at the center of each region in Fig. 15. In Fig. 15a, the transition to open cellular convection within the POC at the end of the first day is evident, with a sharp decrease of $\left\langle N_{\mathrm{a}}\right\rangle$ there and corresponding loss of cloud fraction (Fig. 15f); within the overcast region, $\left\langle N_{\mathrm{a}}\right\rangle$ diminishes less rapidly. Inversion heights fall in both regions after the transition, as depicted in Fig. 15b. This is a response to the reduced domain-mean entrainment resulting from the growth of the POC, shown in Fig. 15c. The falling inversion thins the stratocumulus clouds, reducing LWP (Fig. 15d) and cloud processing of aerosol in the overcast region, in turn allowing $\left\langle N_{\mathrm{a}}\right\rangle$ to increase. This further limits precipitation sinks of both aerosol and cloud water, and overcast LWP begins to recover soon after surface precipitation ceases on day 3 . The inversion height and LWP then increase in unison, and as the cloud thickens, stronger cloud processing and buffering by entrainment dilution (Mechem et al., 2006) arrests the growth of overcast $\left\langle N_{\mathrm{a}}\right\rangle$. This suggests a negative feedback loop, where the coupling between POC area, domain-mean entrainment, and LWP as moderated by $z_{\mathrm{i}}$ stabilizes the system.

Figure 16 shows the nearly equilibrated behavior on day 9.58. Strong latent heating in the upper region of the POC contrasts with continuous radiative cooling of the well-mixed overcast. We hypothesize the $50 \mathrm{~m}$ difference in inversion height between the POC and surrounding overcast represents a balanced response to this gradient in vertically integrated buoyancy. While the POC has diminished in area, drizzle processes are still very active. The cloud base smoothly drops from the edges of the overcast, reflecting the cooler, decoupled POC surface layer, and only the most active drizzle cells have cloud top heights near the inversion. Without the surrounding overcast region, the inversion in the POC region would have collapsed several hundred meters due to the lack of entrainment, while that in the overcast region would have deepened due to the large entrainment there and undergone runaway precipitation feedback, as in Fig. 4. That is, each region holds the other in balance, a dynamically buffered system response in the spirit of Stevens and Feingold (2009).

Interpreting this system in a reduced-complexity, slowmanifold framework, the evolution of each region is controlled by its mean $\left\langle N_{\mathrm{a}}\right\rangle$ and by the coupled evolution of inversion height, i.e., domain-mean entrainment, which is in turn set mainly by the areal fraction of the domain occupied by the overcast region vs the POC. It is unclear exactly what controls the areal fraction of POC to overcast, but reduced POC entrainment couples to domain-wide boundary layer depth, LWP, and aerosol tendencies in a manner that creates a negative feedback on the horizontal expansion of the POC. While we have obtained this behavior by means of an initial aerosol perturbation, this feedback mechanism for POC maintenance should be independent of the perturbation used to trigger the development of open cells; the exact mechanism of POC formation in the real atmosphere remains an open question, and represents an important area for future work.

\section{Conclusions}

We have implemented a new single lognormal mode, doublemoment bulk aerosol scheme coupled to the Morrison microphysics parameterization for the SAM CRM, following the general approach of Ivanova and Leighton (2008). We use this framework to examine the evolution of a steadily forced subtropical stratocumulus cloud-aerosol-precipitation system through different regimes, sensitivity to forcing and initial conditions, and the formation and equilibrium of POCs. To facilitate numerous multiday simulations, all but one of our simulations are two-dimensional.

As in past studies (Mechem et al., 2006; Wang et al., 2010; Kazil et al., 2011), transition from closed-cell stratocumulus to more cumuliform, open-cellular convection occurs via the sharp enhancement of the accretion sink as LWP increases 
(a)

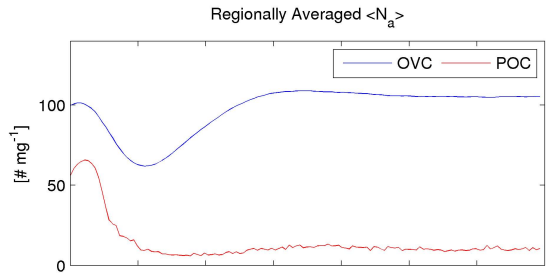

(b)

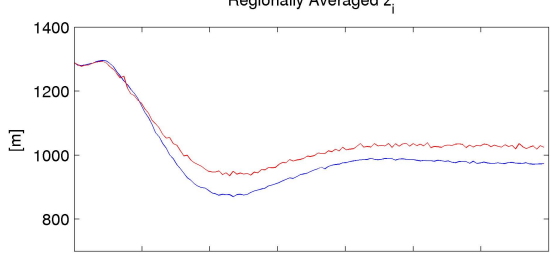

(c)

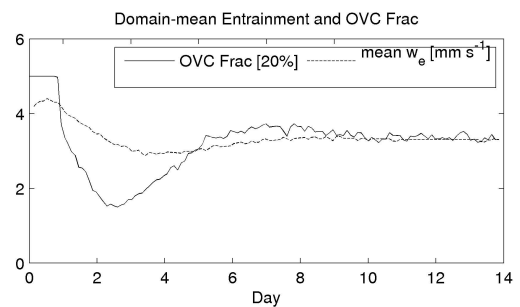

(d)

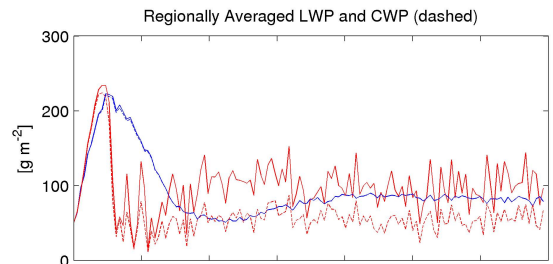

(e)

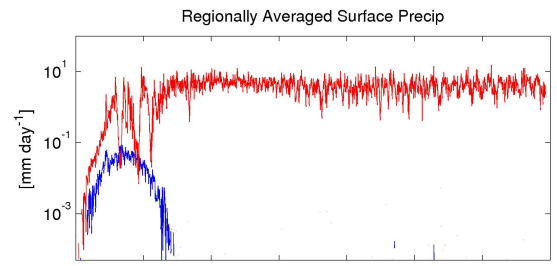

(f)

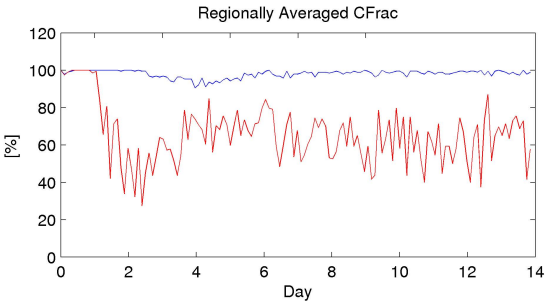

Fig. 15. Time series averaged from $24 \mathrm{~km}$ wide strips centered within the overcast (OVC) and POC. Left column shows panels (a) aerosol number concentration $\left\langle N_{\mathrm{a}}\right\rangle$, (b) inversion height $z_{\mathrm{i}}$, and (c) overcast fraction and domain-mean entrainment $w_{\mathrm{e}}$; right column shows panels (d) LWP (solid) and CWP (dashed), (e) surface precipitation, and (f) cloud fraction.

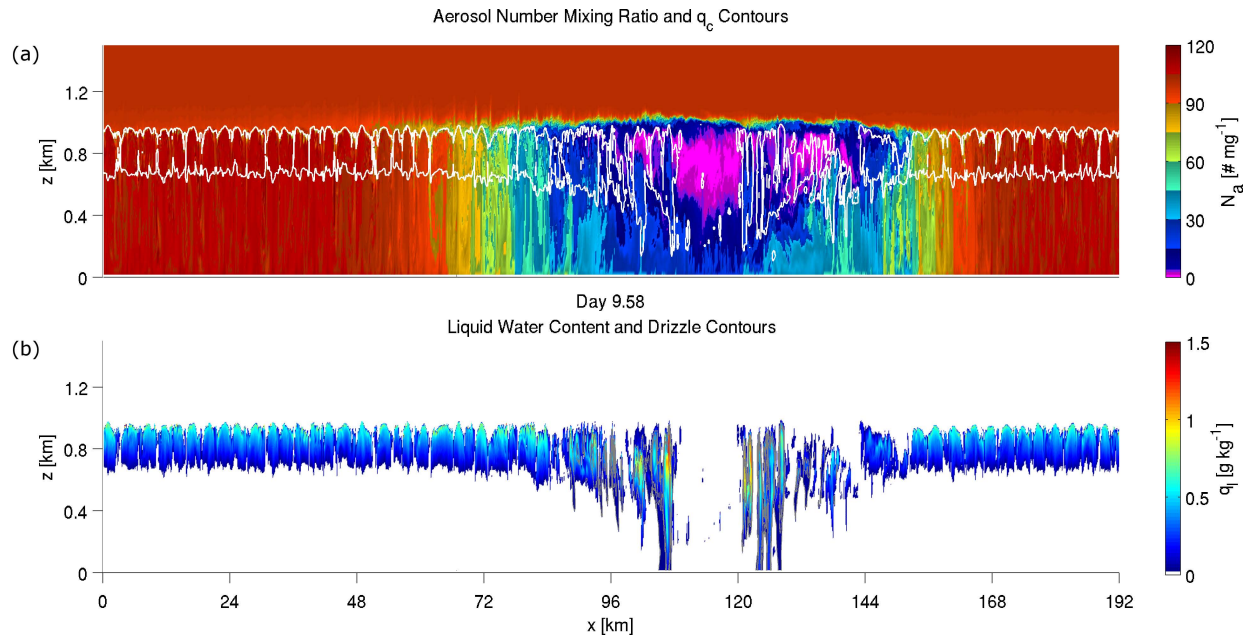

Fig. 16. $x-z$ sections from W5/NA100:50-POC on day 9.58. Panels as in Fig. 12.

and $N_{\mathrm{d}}$ decreases (Feingold and Kreidenweis, 2002). If LWP does not get sufficiently high, this transition never takes place. With diurnally varying insolation, the transition occurs in the early-morning hours, as with observed POC formation.

The cumuliform regime has very low MBL aerosol, high precipitation, and weak entrainment. Over a few days, the mean subsidence shallows the inversion to $600-700 \mathrm{~m}$. In such a shallow MBL, cumulus clouds do not deepen enough to precipitate as much, and the MBL undergoes a transition into a well-mixed structure with more stratocumulus under the capping inversion and more entrainment. In our one 3-D simulation, this shallow stratocumulus layer settles into a shallow, drizzly, low-aerosol steady state; in 2-D the entrainment feedback is stronger and the MBL deepens again into a thick, high-aerosol stratocumulus-topped layer.

In spirit, the long-lived high-aerosol and low-aerosol regimes in our simulations support the bistability hypothesis of Baker and Charlson (1990). A 2-D phase plane 
representation of the evolution of the cloud-aerosol system in terms of boundary layer mean aerosol concentration and inversion height provides a convenient way to identify cloudaerosol regimes and transitions between them, and basins of attraction to the respective regimes.

Another series of runs used a larger domain with a horizontal aerosol gradient to explore the formation of POCs. When initialized with an outer domain $N_{\mathrm{a}}$ of $100 \mathrm{mg}^{-1}$ and an inner $N_{\mathrm{a}}$ of $50 \mathrm{mg}^{-1}$, the inner region transitioned to open-cellular cumuliform convection while the outer region remained well-mixed, closed-cell stratocumulus. The transition of the inner region reduced domain-averaged entrainment, reducing the overall inversion height and reducing cloud thickness and LWP in the outer region, resulting in increased $N_{\mathrm{a}}$ there and providing a negative feedback on growth of the open-cellular region. The resulting POCovercast system appears to be a stable steady state under constant forcing. This is consistent with the observed robustness of POCs, which are rarely observed to close up once formed (Wood et al., 2008).

Future work could involve continued exploration of the phase space using 3-D runs, as well as 3-D runs with realistic time-dependent forcing following an advecting boundary layer air column. Another interesting question is the sensitivity of nascent and fully developed POCs to FT aerosol perturbations, that is, what would it take to close a POC? Lastly, use of a more complete aerosol scheme could provide an important test of the robustness of our results.

\section{Appendix A}

\section{Interstitial scavenging}

A lognormal form $f(A)$ is assumed for the aerosol size spectrum. The number and mass scavenging tendencies are

$$
\begin{aligned}
& \frac{\partial n}{\partial t}=\frac{\partial}{\partial t} \int_{0}^{\infty} f(A) \mathrm{d} A=-\int_{0}^{\infty} \gamma(A) f(A) \mathrm{d} A \\
& \frac{\partial q}{\partial t}=\frac{\pi \rho_{\mathrm{a}}}{6} \frac{\partial}{\partial t} \int_{0}^{\infty} A^{3} f(A) \mathrm{d} A=-\frac{\pi \rho_{\mathrm{a}}}{6} \int_{0}^{\infty} \gamma(A) A^{3} f(A) \mathrm{d} A,
\end{aligned}
$$

where $A$ is the aerosol diameter, $\rho_{\mathrm{a}}$ the aerosol density, and $\gamma(A)$ the scavenging coefficient (e.g., Seinfeld and Pandis, 1998).

$$
\gamma(d)=\frac{\pi}{4} \int_{0}^{\infty}(D+A)^{2}(U(D)-u(A)) E(D, A) F(D) \mathrm{d} D,
$$

where $D$ is the collecting drop diameter, $U(D)$ and $u(A)$ are the respective terminal fall speeds for the collecting drop and aerosol, $F(D)$ is the size distribution of collector drops, and $E(D, A)$ is the collection efficiency. We approximate $\gamma(A)$ by assuming the aerosol diameter and terminal velocity are much smaller than the collector drop diameter and terminal velocity $u(A)$. The collector fall speed has the form $U=a D^{\mathrm{b}}\left(\rho_{0} / \rho\right)^{1 / 2}$ (Khvorostyanov and Curry, 2002). The collector drop size distribution is assumed to follow a generalized gamma distribution $F(D)=N_{0} D^{v} \exp (-\lambda D)$, where $N_{0}$ is the intercept parameter, $v$ the shape parameter, and $\lambda$ is the slope parameter (e.g., Ulbrich, 1983). With the above simplifications, the scavenging coefficient becomes

$\gamma(d)=\frac{\pi a N_{0}}{4} \int_{0}^{\infty} D^{2+\mathrm{b}+v} E(D, A) \exp (-\lambda D) \mathrm{d} D$.

In Morrison et al. (2005) and other double-moment schemes, $N_{0}$ and $\lambda$ may be calculated from the total number $\left(N_{\mathrm{d}}\right.$ for cloud, $N_{\mathrm{r}}$ for rain) and water mass ( $q_{\mathrm{c}}$ for cloud, $q_{\mathrm{r}}$ for rain).

$N_{0}=\frac{N \lambda^{v+1}}{\Gamma(v+1)}$

$\lambda=\left[\frac{\pi \rho_{\mathrm{w}} N}{6 q}(v+3)(v+2)(v+1)\right]^{1 / 3}$

where $\rho_{\mathrm{w}}$ is the density of water.

Collision efficiency is given as the effective collision kernel over the geometric collision kernel, approximated as

$E(D, A) \approx \frac{K(D, A)}{\frac{\pi}{4} D^{2} U(D)}$,

where $K(D, A)$ is the sum of the individual process kernels. For cloud droplets, the included processes are Brownian diffusion, thermophoresis, diffusiophoresis, and turbulent coagulation (using Pruppacher and Klett, 1997, Eqs. 11-59, 17-25, 17-33, and 11-77, respectively). The turbulent kernel currently assumes a fixed value for dissipation in convective clouds of $\epsilon=4.22 \times 10^{-5} \mathrm{~m}^{2} \mathrm{~s}^{-3}$; this will be updated to use the local model values of epsilon in future versions. For rain, $K(D, A)$ is the semi-empirical formulation of Slinn (1983). Appropriate values of sulfate aerosol thermal conductivity for these kernels may be found in Seinfeld and Pandis $(1998$, p. 481). Figure A1 plots $\log E(D, A)$ for aerosol diameter vs. hydrometeor diameter at a pressure of $900 \mathrm{mb}$, temperature of $282 \mathrm{~K}$, and relative humidity $(\mathrm{RH})$ of $100.5 \%$. There is some sensitivity to $\log E(D, A)$ around $\mathrm{RH}$ values near $100 \%$ for aerosol larger than $0.1 \mu \mathrm{m}$ and cloud droplets between 5-20 $\mu \mathrm{m}$; as the version of SAM used here does not include prognostic super-saturation, we choose an in-cloud value of $100.5 \%$. The discontinuity at $D=80 \mu \mathrm{m}$ shows the transition between cloud and rain kernels. Since collision efficiencies for larger hydrometeors and accumulation mode 


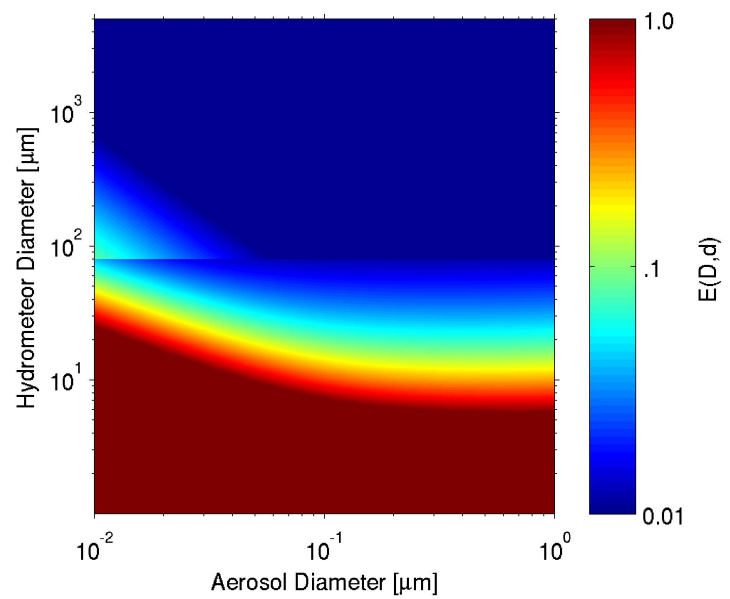

Fig. A1. Plot of collision efficiency as a function of aerosol and hydrometeor diameters at a pressure of $900 \mathrm{mb}$, temperature of $282 \mathrm{~K}$, and relative humidity of $100.5 \%$. The rain collision efficiency is plotted for hydrometeor diameters above $80 \mu \mathrm{m}$; the cloud collision efficiency is plotted below this threshold.

(sub-micron diameter) aerosol are small (mostly below $1 \%$ ), this discontinuity is of little concern. The number and mass scavenging rates (A1) and (A2) are integrated numerically in a method generalizing the approach of Berthet et al. (2010).

Look-up tables of $\gamma(A)$ for cloud and rain as a function of temperature, pressure, $\mathrm{RH}$, and cloud/rain precipitation fluxes are generated on initialization of the scheme. This is done by integrating A3 across a default gamma distribution for cloud and the Marshall-Palmer distribution for rain using Gauss-Laguerre quadrature. Gauss-Hermite quadrature is then used to integrate over the aerosol size distribution using the current values of $N_{\mathrm{a}}, q_{\mathrm{a}}$, and look-up values of $\gamma(A)$ to calculate the scavenging tendencies of $N_{\mathrm{a}}$ and $q_{\mathrm{a}}$. For efficiency, the tendencies are updated once every three time steps and are set to zero after all liquid or aerosol has been removed from a grid box between updates. Future versions of the code will use the prognostic Morrison cloud and rain distributions when numerically integrating (A3) and include an option to calculate tendencies using an approximate analytical approach.

\section{Appendix B}

\section{Model sensitivity to computing environment: a cautionary tale}

We note here that elements of the results presented have altered somewhat since the original publication of this article in discussion paper form. After obtaining an allocation on the Yellowstone cluster maintained by the National Center for Atmospheric Research's Computational Information Systems Laboratory (NCAR CISL), it became possible to perform the parameter sweep presented in Sect. 7. When at- tempting to duplicate the set of original simulations, however, significant changes were evident, including the loss of a previously extant shallow, polluted equilibrium in the W6.5/NA10/Z1300 simulation; all initial conditions now ultimately converged to the deeper equilibrium. Sensitivity to the diurnal cycle diminished, and both small and large domain simulations recovered from the collapsing regime at values of $z_{i}$ between 600 and $700 \mathrm{~m}$, whereas previously the small domain simulations would collapse to depths as shallow as $200 \mathrm{~m}$. Source code was confirmed to be identical between the original system used for simulations and Yellowstone, and tests on Yellowstone using different compilers with a range of optimization flags did not resolve the discrepancy. The discrepancies in model evolution were eventually traced to differences in the shortwave radiative heating rate, which was $10 \%$ larger at cloud top in original simulations, suppressing cloud driven turbulence and reducing entrainment in the collapsing regime. The issue was finally isolated to a bizarre incompatibility involving the compiler and the version of the NetCDF library it was linked to during compilation, which affected the radiation code by way of a corrupted read of transfer coefficients from an NC file.

This episode highlights the difficulty of judging the validity of simulation results produced by complex models on large-scale computing platforms in some situations. Models by their nature have algorithmic sources of error and uncertainty, but users are at least aware of them to some extent. Error and uncertainty introduced through the choice of computational environment, however, represent "unknown unknowns," especially for smaller modeling groups without dedicated software teams. It is our hope that sharing this experience will increase awareness of the potential for errors of this type and encourage efforts to limit them.

\section{Supplementary material related to this article is available online at http://www.atmos-chem-phys.net/13/ 12549/2013/acp-13-12549-2013-supplement.zip.}

Acknowledgements. Thanks to P. Blossey at UW for help with the implementation and debugging of the aerosol scheme. We are also grateful to M. Khairoutdinov of Stony Brook University for maintaining and providing SAM for use in this study. We would like to acknowledge high-performance computing support from Yellowstone (ark:/85065/d7wd3xhc) provided by NCAR's Computational and Information Systems Laboratory, sponsored by the National Science Foundation. The authors gratefully acknowledge support from NSF grants ATM-0745702 and AGS-1242639 and the University of Washington College of the Environment Geoengineering Initiative. Andreas Muhlbauer acknowledges funding received from NSF grant ATM-1102505. This publication is partially funded by JISAO under NOAA cooperative agreement no. NA10OAR4320148, contribution no. 2140.

Edited by: G. Feingold 


\section{References}

Abdul-Razzak, H. and Ghan, S. J.: A parameterization of aerosol activation: 2. Multiple aerosol types, J. Geophys. Res., 105, 683-684, 2000.

Ackerman, A. S., Toon, O. B., and Hobbs, P. V.: Dissipation of marine stratiform clouds and collapse of the marine boundary layer due to the depletion of cloud condensation nuclei by clouds, Science, 262, 226-229, doi:10.1126/science.262.5131.226, 1993.

Ackerman, A. S., Toon, O. B., and Hobbs, P. V.: Reassessing the dependence of cloud condensation nucleus concentration on formation rate, Nature, 367, 445-447, doi:10.1038/367445a0, 1994.

Ackerman, A., Toon, O. B., Stevens, D. E., and Coakley Jr., J. A.: Enhancement of cloud cover and suppression of nocturnal drizzle in stratocumulus polluted by haze, Geophys. Res. Lett., 30, 1381, doi:10.1029/2002GL016634, 2003.

Ackerman, A., Kirkpatrick, M. P., Stevens, D. E., and Toon, O. B.: The impact of humidity above stratiform clouds on indirect aerosol climate forcing, Nature, 432, 1014-1017, 2004.

Albrecht, B. A.: Aerosols, Cloud Microphysics, and Fractional Cloudiness, Science, 245, 1227-1230, 1989.

Allen, G., Coe, H., Clarke, A., Bretherton, C., Wood, R., Abel, S. J., Barrett, P., Brown, P., George, R., Freitag, S., McNaughton, C., Howell, S., Shank, L., Kapustin, V., Brekhovskikh, V., Kleinman, L., Lee, Y.-N., Springston, S., Toniazzo, T., Krejci, R., Fochesatto, J., Shaw, G., Krecl, P., Brooks, B., McMeeking, G., Bower, K. N., Williams, P. I., Crosier, J., Crawford, I., Connolly, P., Allan, J. D., Covert, D., Bandy, A. R., Russell, L. M., Trembath, J., Bart, M., McQuaid, J. B., Wang, J., and Chand, D.: South East Pacific atmospheric composition and variability sampled along $20^{\circ} \mathrm{S}$ during VOCALS-REx, Atmos. Chem. Phys., 11, 5237-5262, doi:10.5194/acp-11-5237-2011, 2011.

Baker, M. B. and Charlson, R. J.: Bistability of CCN concentrations and thermodynamics in the cloud-topped boundary layer, Nature, 345, 142-145, 1990.

Baker, M. B., Breidenthal, R. E., Choularton, T. W., and Latham, J.: The effects of turbulent mixing in clouds, J. Atmos. Sci., 41, 299-304, doi:10.1175/15200469(1984)041<0299:TEOTMI>2.0.CO;2, 1984.

Berner, A. H., Bretherton, C. S., and Wood, R.: Large-eddy simulation of mesoscale dynamics and entrainment around a pocket of open cells observed in VOCALS-REx RF06, Atmos. Chem. Phys., 11, 10525-10540, doi:10.5194/acp-11-10525-2011, 2011.

Berthet, S., Leriche, M., Pinty, J.-P., Cuesta, J., and Pigeon, G.: Scavenging of aerosol particles by rain in a cloud resolving model, Atmos. Res., 96, 325-336, doi:10.1016/j.atmosres.2009.09.015, 2010.

Blossey, P. N. and Durran, D. R.: Selective monotonicity preservation in scalar advection, J. Comp. Physiol., 227, 5160-5183, doi:10.1016/j.jcp.2008.01.043, 2008.

Bony, S. and DuFresne, J.-L.: Marine boundary layer clouds at the heart of tropical cloud feedback uncertainties in climate models, Geophys. Res. Lett., 32, 2-5, doi:10.1029/2005GL023851, 2005.

Burnet, F. and Brenguier, J.-L.: Observational study of the entrainment-mixing process in warm convective clouds, J. Atmos. Sci., 64, 1995-2011, doi:10.1175/JAS3928.1, 2007.

Bretherton, C. S., Uttal, T., Fairall, C. W. , Yuter, S., Weller, R., Baumgardner, D., Comstock, K., and Wood, R.: The EPIC 2001 stratocumulus study, B. Am. Meteorol. Soc., 85, 967-977, 2004.
Bretherton, C. S., Uchida, J., and Blossey, P. N.: Slow manifolds and multiple equilibria in stratocumulus-capped boundary layers, J. Adv. Model. Earth Syst., 2, 14 pp., doi:10.3894/JAMES.2010.2.14, 2010.

Clarke, A. D.: Atmospheric nuclei in the Pacific midtroposphere: Their nature, concentration, and evolution, J. Geophys. Res., 98, 20633, doi:10.1029/93JD00797, 1993.

Clarke, A. D., Li, Z., and Litchy, M.: Aerosol dynamics in the equatorial Pacific marine boundary layer: Microphysics, diurnal cycles and entrainment, Geophys. Res. Lett., 23, 733-736, 1996.

Clarke, A. D., Owens, S. R., and Zhou, J.: An ultrafine sea-salt flux from breaking waves: Implications for cloud condensation nuclei in the remote marine atmosphere, J. Geophys. Res., 111, 1-14, doi:10.1029/2005JD006565, 2006.

Comstock, K., Bretherton, C. S., and Yuter, S.: Mesoscale variability and drizzle in Southeast Pacific stratocumulus, J. Atmos. Sci., 62, 3792-3807, 2005.

Comstock, K. K., Yuter, S. E., Wood, R., and Bretherton, C. S.: The three-dimensional structure and kinematics of drizzling stratocumulus, Mon. Weather Rev., 135, 3767-3784, doi:10.1175/2007MWR1944.1, 2007.

Dai, A. and Deser, C.: Diurnal and semidiurnal variations in global surface wind and divergence fields, J. Geophys. Res., 104, 31109 , doi:10.1029/1999JD900927, 1999.

Deardorff, J.: Stratocumulus-capped mixed layers derived from a three-dimensional model, Bound.-Lay. Meteorol., 18, 495-527, 1980.

Feingold, G. and Kreidenweis, S. M.: Cloud processing of aerosol as modeled by a large eddy simulation with coupled microphysics and aqueous chemistry, J. Geophys. Res., 107, 4687, doi:10.1029/2002JD002054, 2002.

Feingold, G., Kreidenweis, S. M., Stevens, B., and Cotton, W. R.: Numerical simulations of stratocumulus processing of cloud condensation nuclei through collision-coalescence, J. Geophys. Res., 101, 21391, doi:10.1029/96JD01552, 1996.

Feingold, G., Koren, I., Wang, H., Xue, H., and Brewer, W. A. Precipitation-generated oscillations in open cellular cloud fields, Nature, 466, 849-852, doi:10.1038/nature09314, 2010.

Flossmann, A. I., Hall, W. D., and Pruppacher, H. R.: A theoretical study of the wet removal of atmospheric pollutants. Part I: The redistribution of aerosol particles captured through nucleation and impaction scavenging by growing cloud drops, J. Atmos. Sci., 42, 583-606, doi:10.1175/15200469(1985)042<0583:ATSOTW>2.0.CO;2, 1985.

Hartmann, D. L., Ockert-Bell, M. E., and Michelsen, M. L.: The effect of cloud type on Earth's energy balance: Global analysis, J. Climate, 5, 1281-1304, 1992.

Ivanova, I. T. and Leighton, H. G.: Aerosol-cloud interactions in a mesoscale model. Part I: Sensitivity to activation and collision-coalescence, J. Atmos. Sci., 65, 289-308, doi:10.1175/2007JAS2207.1, 2008.

Kazil, J., Wang, H., Feingold, G., Clarke, A. D., Snider, J. R., and Bandy, A. R.: Modeling chemical and aerosol processes in the transition from closed to open cells during VOCALS-REx, Atmos. Chem. Phys., 11, 7491-7514, doi:10.5194/acp-11-74912011, 2011.

Khairoutdinov, M. F. and Kogan, Y. L.: A new cloud physics parameterization in a large-eddy simulation model of marine stratocumulus, Mon. Weather Rev., 128, 229-243, 
doi:10.1175/1520-0493(2000)128<0229:ANCPPI>2.0.CO;2, 2000.

Khairoutdinov, M. F. and Randall, D. A.: Cloud resolving modeling of the ARM summer 1997 IOP: Model formulation, results, uncertainties, and sensitivities, J. Atmos. Sci., 60, 607-625, 2003.

Khvorostyanov, V. I. and Curry, J. A.: Terminal velocities of droplets and crystals: Power laws with continuous parameters over the size spectrum, J. Atmos Sci., 59, 1872-1884, doi:10.1175/1520-0469(2002)059<1872:TVODAC >2.0.CO;2, 2002.

Kogan, Y. L., Khairoutdinov, M. P., Lilly, D. K., Kogan, Z. N., and Liu, Q.: Modeling of stratocumulus cloud layers in a large eddy simulation model with explicit microphysics, J. Atmos. Sci., 52, 2923-2940, doi:10.1175/15200469(1995)052<2923:MOSCLI>2.0.CO;2, 1995.

Koren, I. and Feingold, G.: Aerosol-cloud-precipitation system as a predator-prey problem, P. Natl. Acad. Sci., 108, 12227-12232, 2011.

Liou, K. N. and Ou, S. C.: The role of cloud microphysical processes in climate: An assessment from a onedimensional perspective, J. Geophys. Res., 94, 2156-2202, doi:10.1029/JD094iD06p08599, 1989.

Mechem, D. B. and Kogan, Y. L.: Simulating the transition from drizzling marine stratocumulus to boundary layer cumulus with a mesoscale model, Mon. Weather Rev., 131, 2342-2360, doi:10.1175/1520-0493(2003)131<2342:STTFDM>2.0.CO;2, 2003.

Mechem, D. B., Robinson, P. C., and Kogan, Y. L.: Processing of cloud condensation nuclei by collision-coalescence in a mesoscale model, J. Geophys. Res., 111, D18204, doi:10.1029/2006JD007183, 2006.

Mitra, S. K., Brinkmann, J., and Pruppacher, H. R.: A wind tunnel study on the drop-to-particle conversion, J. Aerosol Sci., 23, 245-256, doi:10.1016/0021-8502(92)90326-Q, 1992.

Mlawer, E. J., Taubman, S. J., Brown, P. D., Iacono, M. J., and Clough, S. A.: Radiative transfer for inhomogeneous atmospheres: RRTM, a validated correlated-k model for the longwave, J. Geophys. Res., 102, 16663, doi:10.1029/97JD00237, 1997.

Morrison, H. and Grabowski, W. W.: Modeling supersaturation and subgrid-scale mixing with two-moment bulk warm microphysics, J. Atmos. Sci., 65, 792-812, doi:10.1175/2007JAS2374.1, 2008.

Morrison, H., Curry, J. A., and Khvorostyanov, V. I.: A new doublemoment microphysics parameterization for application in cloud and climate models. Part I: Description, J. Atmos. Sci., 62, 1665-1677, doi:10.1175/JAS3446.1, 2005.

Petters, M. D., Snider, J. R., Stevens, B., Vali, G., Faloona, I., and Russell, L. M.: Accumulation mode aerosol, pockets of open cells, and particle nucleation in the remote subtropical Pacific marine boundary layer, J. Geophys. Res., 111, D02206, doi:10.1029/2004JD005694, 2006.

Pruppacher, H. R. and Klett, J. D.: Microphysics of clouds and precipitation, Kluwer Academic Publishers, Dordrecht, Boston, London, 954 pp., 1997.

Quaas, J., Ming, Y., Menon, S., Takemura, T., Wang, M., Penner, J. E., Gettelman, A., Lohmann, U., Bellouin, N., Boucher, O., Sayer, A. M., Thomas, G. E., McComiskey, A., Feingold, G., Hoose, C., Kristjánsson, J. E., Liu, X., Balkanski, Y., Donner, L. J., Ginoux, P. A., Stier, P., Grandey, B., Feichter, J., Sednev, I.,
Bauer, S. E., Koch, D., Grainger, R. G., Kirkevåg, A., Iversen, T., Seland, Ø., Easter, R., Ghan, S. J., Rasch, P. J., Morrison, H., Lamarque, J.-F., Iacono, M. J., Kinne, S., and Schulz, M.: Aerosol indirect effects - general circulation model intercomparison and evaluation with satellite data, Atmos. Chem. Phys., 9, 8697-8717, doi:10.5194/acp-9-8697-2009, 2009.

Savic-Jovcic, V. and Stevens, B.: The structure and mesoscale organization of precipitating stratocumulus, J. Atmos. Sci., 65, 1587-1605, 2008.

Schubert, W. H., Wakefield, J. S., Steiner, E. J., and Cox, S. K.: Marine stratocumulus convection. Part I: Governing equations and horizontally homogeneous solutions, J. Atmos. Sci., 36, 1286-1307, 1979.

Seinfeld, J. H. and Pandis, S. N.: Atmospheric chemistry and physics, John Wiley and Sons, 605 Third Avenue, New York, NY, 1998.

Slinn, W. G. N.: Precipitation scavenging, in: Atmospheric sciences and power production - 1979, chap. 11, Division of Biomedical Environmental Research, US Department of Energy, Washington D. C., 1983.

Stevens, B. and Feingold, G.: Untangling aerosol effects on clouds and precipitation in a buffered system, Nature, 461, 607-613, doi:10.1038/nature08281, 2009.

Stevens, B., Cotton, W. R., Feingold, G., and Moeng, C.-H.: Large-eddy simulations of strongly precipitating, shallow, stratocumulus-topped boundary layers, J. Atmos. Sci., 55, 3616-3638, doi:10.1175/15200469(1998)055<3616:LESOSP>2.0.CO;2, 1998.

Stevens, B., Lenschow, D. H., Vali, G., Gerber, H., Bandy, A., Blomquist, B., Brenguier, J.-L., Bretherton, C. S., Burnet, F., Campos, T., Chai, S., Faloona, I., Friesen, D., Haimov, S., Laursen, K., Lilly, D. K., Loehrer, S. M., Malinowski, S. P., Morely, B., Petters, M. D., Rogers, D. C., Russell, L. M., Savic-Jovcic, V., Snider, J. R., Straub, D., Szumowski, J., Takagi, H., Thorton, D. C., Tschudi, M., Twohy, C., Wetzel, M., and Van Zanten, M. C.: Dynamics and chemistry of marine stratocumulus-DYCOMS-II, B. Am. Meteorol. Soc., 84, 579-594, 2003.

Stevens, B., Vali, G., Comstock, K., Wood, R., van Zanten, M. C., Austin, P. H., Bretherton, C. S., and Lenschow, D. H.: Pockets of open cells and drizzle in marine stratocumulus, B. Am. Meteorol. Soc., 86, 51-57, 2005.

Twomey, S.: The influence of pollution on the shortwave albedo of clouds, J. Atmos. Sci., 34, 1149-1152, 1977.

Ulbrich, C. W.: Natural variations in the analytical form of the rain drop size distribution, J. Clim. Appl. Meteorol., 22, 1764-1775, 1983.

Van Zanten, M. C. and Stevens, B.: Observations of drizzle in nocturnal marine stratocumulus, J. Atmos. Sci., 62, 88-106, 2005.

Wang, H. and Feingold, G.: Modeling mesoscale cellular structures and drizzle in marine stratocumulus. Part I: Impact of drizzle on the formation and evolution of open cells, J. Atmos. Sci., 66, 3237-3256, 2009a.

Wang, H. and Feingold, G.: Modeling mesoscale cellular structures and drizzle in marine stratocumulus. Part II: The microphysics and dynamics of the boundary region between open and closed cells, J. Atmos. Sci., 66, 3257-3275, 2009b.

Wang, H., Feingold, G., Wood, R., and Kazil, J.: Modelling microphysical and meteorological controls on precipitation and cloud 
cellular structures in Southeast Pacific stratocumulus, Atmos. Chem. Phys., 10, 6347-6362, doi:10.5194/acp-10-6347-2010, 2010.

Wood, R. and Hartmann, D. L.: Spatial variability of liquid water path in marine low cloud: The importance of mesoscale cellular convection, J. Climate, 19, 1748-1764, doi:10.1175/JCLI3702.1, 2006.

Wood, R., Comstock, K. K., Bretherton, C. S., Cornish, C., Tomlinson, J., Collins, D. R., and Fairall, C.: Open cellular structure in marine stratocumulus sheets, J. Geophys. Res., 113, D12207, doi:10.1029/2007JD009371, 2008.

Wood, R., Mechoso, C. R., Bretherton, C. S., Weller, R. A., Huebert, B., Straneo, F., Albrecht, B. A., Coe, H., Allen, G., Vaughan, G., Daum, P., Fairall, C., Chand, D., Gallardo Klenner, L., Garreaud, R., Grados, C., Covert, D. S., Bates, T. S., Krejci, R., Russell, L. M., de Szoeke, S., Brewer, A., Yuter, S. E., Springston, S. R., Chaigneau, A., Toniazzo, T., Minnis, P., Palikonda, R., Abel, S. J., Brown, W. O. J., Williams, S., Fochesatto, J., Brioude, J., and Bower, K. N.: The VAMOS Ocean-Cloud-AtmosphereLand Study Regional Experiment (VOCALS-REx): goals, platforms, and field operations, Atmos. Chem. Phys., 11, 627-654, doi:10.5194/acp-11-627-2011, 2011.
Wood, R., Bretherton, C. S., Leon, D., Clarke, A. D., Zuidema, P., Allen, G., and Coe, H.: An aircraft case study of the spatial transition from closed to open mesoscale cellular convection over the Southeast Pacific, Atmos. Chem. Phys., 11, 2341-2370, doi:10.5194/acp-11-2341-2011, 2011.

Xue, H., Feingold, G., and Stevens, B.: Aerosol effects on clouds, precipitation, and the organization of shallow cumulus convection, J. Atmos. Sci., 65, 392-406, doi:10.1175/2007JAS2428.1, 2008.

Zhang, L.: Numerical studies of aerosol scavenging by low-level, warm stratiform clouds and precipitation, Atmos. Environ., 38, 4653-4665, doi:10.1016/j.atmosenv.2004.05.042, 2004. 